Neurosurg Focus 27 (3):E11, 2009

\title{
Neuronavigation: geneology, reality, and prospects
}

\author{
Yavor EnChev, M.D., Ph.D. \\ Department of Neurosurgery, Medical University-Sofia, Bulgaria
}

\begin{abstract}
Currently, neuronavigation is an indivisible and indispensable part of the neurosurgical reality with a significant potential impact in each neurosurgical procedure. The history of neuronavigation is quite short $(<3$ decades $)$, but full of highly promising achievements. The advent of neuronavigation would be unimaginable without the development of imaging technology, electronics, robotics, and space technology. The history of neuroradiology is reviewed briefly parallel with the detailed evolution of frame-based stereotaxy and its successor-neuronavigation. The historic milestones and the state of the art of neuronavigation are discussed in a genealogical manner. The future trends of neuronavigation as integrated with intraoperative CT, MR, and ultrasonography, as well as with robotic systems are outlined.(DOI: 10.3171/2009.6.FOCUS09109)
\end{abstract}

$\begin{array}{llll}\text { KEY WoRDS } & \text { neuroradiology } & \bullet & \text { frame-based stereotaxy } \\ \text { neuronavigation } & \bullet & \text { robotics }\end{array}$

$\mathrm{N}$ EURONAVIGATION simultaneously represents a complex, multimodal, information-based, widely adaptable technique, method, or device using frameless stereotaxy for precise intraoperative guidance, orientation, and localization, with consequently greater surgical precision and possibilities for preoperative virtual simulation and postoperative analysis of the surgical procedure.

\section{Neuronavigation and Neurosurgery}

Neurosurgery will never be the same after the introduction of neuronavigation. The possibilities for the application of neuronavigation to contemporary neurosurgery are practically unlimited, with the potential to supply better guidance, orientation, and localization, and hence a higher confidence level for the surgeon and an improved outcome for the patient. ${ }^{24-29,68}$

\section{Genealogy of Neuronavigation}

Neuronavigation is an emanation of the development of neuroradiology. Neuronavigation is the ultimate achievement of the aspiration to transfer multimodal image information in the operative field. The genealogical relations of neuronavigation, as a successor of frame-based

Abbreviations used in this paper: $\mathrm{DW}=$ diffusion weighted; $\mathrm{fMR}=$ functional $\mathrm{MR}$; iCT = intraoperative CT; iMR = intraoperative MR; LED = light-emitting diode; $\mathrm{MEG}=$ magnetoencephalography. streotaxy with CT, MR imaging, SPECT, PET, and ultrasonography are indisputable. The aim of the present study was to review the fascinating past, the glorious present, and the exciting future of neuronavigation (Table 1).

\section{History of Neuroradiology}

Until the end of the 19th century, the only way to look into patients' bodies was through invasive procedures.

In 1895, Wilhelm Conrad Roentgen discovered xrays, and the imaging of the CNS began with radiographs (plain roentgenograms) of the skull.54

In 1918, Walter Dandy, a prominent neurosurgeon at Johns Hopkins Hospital, introduced ventriculography, ${ }^{20}$ and 1 year later reported on the first use of pneumoencephalography. ${ }^{19}$

In 1927, Egas Moniz, a Portuguese neurologist, introduced opacification of the carotid artery with contrast medium, using a solution of sodium iodide. ${ }^{62}$

However, planar radiographs were not satisfactory, and clinicians urged the radiologists to provide better images.

The methods of brain imaging were profoundly and irreversibly changed with the subsequent invention and introduction of the contemporary imaging techniques. The history of CT, 4,16,42,70,77,78,82,91,97 MR imaging, 5,8,13,18,21,30,31,33, 37,40,43,49-53,59,60,63,66,67,69,85 SPECT, ${ }^{38,48}$ PET, $1,8,12,48,86$ and ultrasonography, ${ }_{10,17,22,23,45,56,58,81,89,92}$ representing a fundamental and integral part of the history of neuronavigation, has been thoroughly described and analyzed in the literature (Table 1). 
TABLE 1: Summary of historical milestones of CT, MRI, SPECT, PET, and ultrasonography in parallel with the evolution of the frame-based stereotaxy and neuronavigation*

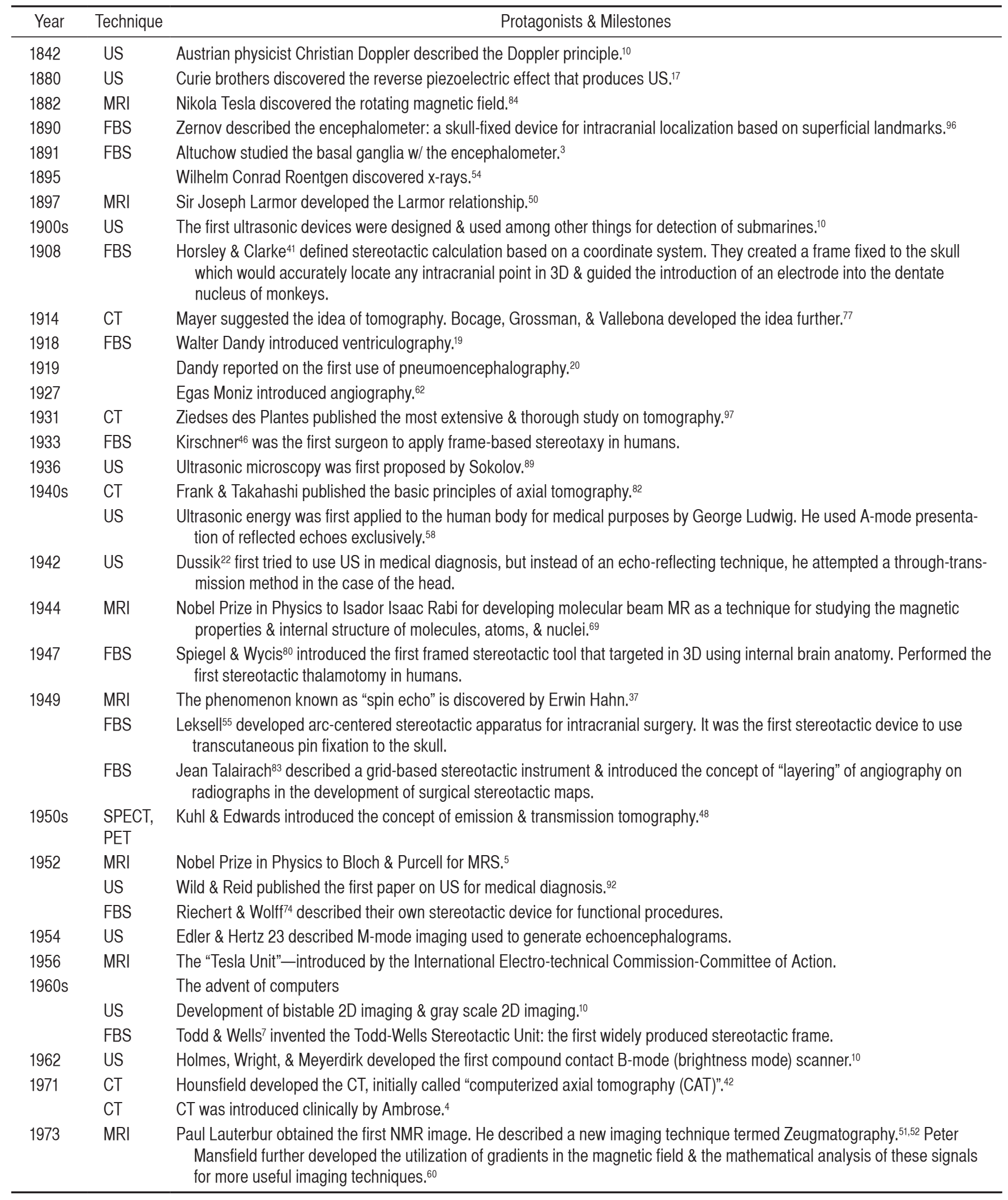

(continued) 
Neuronavigation: past, present, and future

TABLE 1: Summary of historical milestones of CT, MRI, SPECT, PET, and ultrasonography in parallel with the evolution of the frame-based stereotaxy and neuronavigation* (continued)

\begin{tabular}{|c|c|c|}
\hline Year & Technique & Protagonists \& Milestones \\
\hline \multirow[t]{2}{*}{1974} & MRI & Raymond Damadian patented the design \& use of NMR for detecting cancer.18 \\
\hline & US & Kessler ${ }^{45}$ developed the scanning laser acoustic microscope. \\
\hline \multirow[t]{3}{*}{1975} & MRI & Richard Ernst introduced 2D NMR ("NMR Fourier Zeugmatography"). ${ }^{30}$ \\
\hline & US & Lemons \& Quate ${ }^{56}$ described the biomedical application of the scanning acoustic microscope. \\
\hline & PET & $\begin{array}{l}\text { Ter-Pogossian et al. }{ }^{84} \text { developed an apparatus for obtaining transaxial emission images of organ sections containing positron- } \\
\text { emitting radiopharmaceuticals. }\end{array}$ \\
\hline 1976 & PET & Alavi ${ }^{1}$ was the first to administer $18 \mathrm{~F}-\mathrm{FDG}$, the most commonly used PET scanning isotope carrier, to humans. \\
\hline 1977 & MRI & Raymond Damadian produced the first MR scanner (Indomitable). \\
\hline \multirow[t]{4}{*}{1979} & CT & The Nobel Prize in Physiology or Medicine was awarded to Hounsfield ${ }^{42} \&$ Cormack $^{16}$ for the development of CT. \\
\hline & CT & Shalit et al. ${ }^{78}$ described the first neurosurgical procedure guided by iCT. \\
\hline & US & Geoff Stevenson first demonstrated color Doppler. ${ }^{81}$ \\
\hline & FBS & $\begin{array}{l}\text { Brown, Roberts, \& Wells developed a stereotactic instrument w/ ability to translate CT imaging data to the operating } \\
\text { room. } 6,39,90 \text { Subsequent developments led to introduction of flexible Cosman-Roberts-Wells stereotactic system. }\end{array}$ \\
\hline 1980s & CT & Single-slice helical CT scanners. ${ }^{91}$ \\
\hline \multirow[t]{2}{*}{1986} & MRI & The technique of rapid acquisition w/ relaxation enhancement (RARE) — Hennig, Nauerth, \& Friedburg.40 \\
\hline & $\begin{array}{l}\text { NN } \\
\text { BIRTHDAY }\end{array}$ & $\begin{array}{l}\text { David Roberts et al. developed concept of frameless stereotaxy or NN \& described the first NN system. }{ }^{75} \text { Roberts' device was } \\
\text { composed of an operating microscope on a solenoid floating stand and tracked in 3D by a sonic digitizer. }\end{array}$ \\
\hline \multirow[t]{4}{*}{1987} & MRI & Dumoulin ${ }^{21}$ patented MRA. \\
\hline & FBS & $\begin{array}{l}\text { Young }{ }^{93} \text { reported a stereotactic system based on a robotics model. The robotic CT stereotactic system was mounted in a } \\
\text { special operating suite, containing a CT scanner \& adjacent computer room. }\end{array}$ \\
\hline & NN & $\begin{array}{l}\text { Watanabe }{ }^{88} \text { developed multiaxis mechanical measuring arms equipped w/ potentiometric angular sensors \& video equipment } \\
\text { for digitizing of CT scans from conventional films. }\end{array}$ \\
\hline & NN & $\begin{array}{l}\text { Reinhardt² developed multiaxis mechanical measuring arms equipped w/ potentiometric angular sensors \& video equipment } \\
\text { for digitizing of the CT scans from conventional films. }\end{array}$ \\
\hline 1988 & MRI & Magnevist (Gd-DTPA dimeglumine) — Schering \\
\hline \multirow[t]{3}{*}{ 1990s } & US & $\begin{array}{l}\text { Most of the really major advances in ultrasonic imaging have resulted from technology push: real-time scanning, endoluminal } \\
\text { \& intravascular scanning, Doppler blood flow detection, pulsed Doppler \& duplex scanning, color flow imaging, 3D display, } \\
\text { contrast agents, \& harmonic imaging. } .^{10}\end{array}$ \\
\hline & CT & Multislice CT Scanning ${ }^{91}$ \\
\hline & MRI & Introduction of the modalities of DW-MRI (tractography) \& PW-MRI. \\
\hline \multirow[t]{3}{*}{1991} & MRI & Nobel Prize in Chemistry — Richard Ernst — high-resolution NMR spectroscopy. ${ }^{31}$ \\
\hline & MRI & $\begin{array}{l}\text { fMRI — independently by the University of Minnesota's Center for MR Research \& Massachusetts General Hospital's MR } \\
\text { Center. }\end{array}$ \\
\hline & NN & Kato et al. ${ }^{44}$ introduced a frameless, armless navigational system based on magnetic sources. \\
\hline \multirow[t]{2}{*}{1992} & MRI & The BOLD fMRI technique for mapping neuronal activation was first demonstrated in the human brain. $8,49,67$ \\
\hline & FBS & $\begin{array}{l}\text { Benabid et al.11 described the development of a } 6 \text {-axis stereotactic robot that had been linked to a stereotactic frame for } \\
\text { routine stereotactic procedures. }\end{array}$ \\
\hline \multirow[t]{5}{*}{1993} & SPECT & Hasegawa et al. ${ }^{38}$ developed first combined clinical CT \& SPECT prototype scanner. \\
\hline & NN & Reinhardt et al. reported an armless navigation system which used a pointer emitting US signals. ${ }^{73}$ \\
\hline & NN & $\begin{array}{l}\text { Barnet et al. }{ }^{9} \text { described a technique of "frameless" stereotaxy. The system was composed of a hand-held probe containing } 2 \\
\text { ultrasonic emitters, a microphone array that is rigidly affixed to the operating table in proximity to the surgical field, hard- } \\
\text { ware to control \& detect timing of signal production \& reception, \& a computer workstation w/ software to calculate \& pres- } \\
\text { ent the location of the probe tip on reconstructed neuroimaging studies. Unlike previously reported mechanical or sonic } \\
\text { navigational devices, this system was adaptable to a wide array of neurosurgical instruments, allowed free movement of } \\
\text { the operating table \& conventional patient draping, \& had accuracy which rivaled that of frame stereotaxy. }\end{array}$ \\
\hline & NN & $\begin{array}{l}\text { Zamorano et al. }{ }^{95} \text { reported a NN device based on optoelectronic measuring principles. The infrared LEDs were applied as } \\
\text { emitting sources. }\end{array}$ \\
\hline & NN & $\begin{array}{l}\text { Koivukangas et al. }{ }^{47} \text { reported a computer-assisted NN system consisting of a neuronavigator arm w/ } 6 \text { degrees of freedom } \\
\& \text { high-precision potentiometers to indicate joint movements. Intraop US verified the accuracy of the neuronavigator \& } \\
\text { checked the results of the procedures. }\end{array}$ \\
\hline
\end{tabular}

(continued) 
TABLE 1: Summary of historical milestones of CT, MRI, SPECT, PET, and ultrasonography in parallel with the evolution of the frame-based stereotaxy and neuronavigation* (continued)

\begin{tabular}{|c|c|c|}
\hline Year & Technique & Protagonists \& Milestones \\
\hline \multirow[t]{2}{*}{1995} & NN & $\begin{array}{l}\text { Performance of the first neuronavigated neurosurgical procedure in iMRI (the } 0.5-T \text { suite widely known as the "double } \\
\text { doughnut" magnet), which was integrated w/ a LED-based flashpoint navigational system for tracking w/in the 3D space at the } \\
\text { center of the magnet. }{ }^{13}\end{array}$ \\
\hline & MRI & The first iMRI setup—the Brigham \& Women's Hospital in Boston, \& General Electric Medical Systems. ${ }^{13,33}$ \\
\hline 1997 & NN & Tronnier et al. ${ }^{87}$ described 0.2-T iMRI, installed adjacent to the operating theater, for intraop update of the NN data sets. \\
\hline \multirow[t]{3}{*}{1998} & PET & First prototype PET-CT scanner is designed \& built by CTI PET Systems. ${ }^{12}$ \\
\hline & NN & $\begin{array}{l}\text { Matula et al. } .^{61} \text { connected a fixed iCT to a LED-based navigation in one operating room. The patients were positioned on a } \\
\text { specially developed scanner table, which permitted movement from a scanning position to the operating position at any } \\
\text { time during surgery. The procedure was completed w/ updated navigational data. }\end{array}$ \\
\hline & NN & $\begin{array}{l}\text { Grunert et al. }{ }^{36} \text { reported their concept: to adapt a mobile CT scanner to an NN system. Slices were obtained by gantry trans- } \\
\text { lation \& not by CT table movement. Updated CT image data were matched onto the preop CT data set. }\end{array}$ \\
\hline \multirow[t]{2}{*}{1999} & NN & $\begin{array}{l}\text { Ganslandt et al. }{ }^{32} \text { superimposed MEG-source localizations onto a 3D MR image, \& the image data set was then implemented } \\
\text { into an NN system. }\end{array}$ \\
\hline & NN & $\begin{array}{l}\text { Nimsky et al }{ }^{.6} \text { described functional NN based on fusion of fMRI \& MEG data w/ an anatomic 3D MR image set. The matched } \\
\text { 3D image data set was transferred to the navigation microscope \& displayed in it operating viewing field during surgery. }\end{array}$ \\
\hline 1999 & NN & $\begin{array}{l}\text { Samset \& Hirschberg }{ }^{76} \text { described adaptation of a standard NN system into a 0.5-T iMRI scanner. The scanner had a } 60-\mathrm{cm}- \\
\text { wide vertical gap where both imaging \& surgery are conducted \& in-bore infrared linear cameras \& monitors for NN. }\end{array}$ \\
\hline 2000 & NN & $\begin{array}{l}\text { Gronningsaeter et al }{ }^{34} \text { described the integration of an optical NN system into a US scanner. Single-rack system was devel- } \\
\text { oped which enabled the neurosurgeon to perform frameless, armless neuronavigation using preop MR or CT images \& } \\
\text { intraop 3D US data. }\end{array}$ \\
\hline \multirow[t]{4}{*}{2001} & PET & The first commercially available PET-CT scanner was announced (Discovery LS, GE Healthcare). ${ }^{86}$ \\
\hline & NN & Braun et al..$^{14}$ reported the first case of direct integration of fMRI \& PET data into cranial NN. \\
\hline & NN & $\begin{array}{l}\text { Nimsky et al. }{ }^{65} \text { reported a new concept of anatomic \& functional microscope-based NN combined w/ iMRI by positioning a } \\
\text { new navigation microscope w/in the fringe field of the MRI scanner. }\end{array}$ \\
\hline & NN & Zaaroor et al. ${ }^{94}$ reported novel electromagnetic NN system. \\
\hline 2002 & NN & Zimmermann et al. ${ }^{98}$ described their preliminary experience w/ robot-assisted neuronavigated neuroendoscopy. \\
\hline \multirow[t]{3}{*}{2003} & MRI & Nobel Prize in Medicine or Physiology to Paul Lauterbur \& Peter Mansfield for invention of MRI.53,59 \\
\hline & NN & $\begin{array}{l}\text { Nakao et al. }{ }^{64} \text { reported a technique for complete updating of the } \mathrm{NN} \text { w/ the aid of a mobile CT scanner used to acquire intraop } \\
\text { images for a subsequent new registration. }\end{array}$ \\
\hline & NN & $\begin{array}{l}\text { Lindseth et al. }{ }^{57} \text { reported an image fusion between preop MRI \& intraop 3D US in US-based NN for visualizing the brain shift } \\
\text { \& improving interpretation. }\end{array}$ \\
\hline 2005 & NN & $\begin{array}{l}\text { Coenen et al. }{ }^{15} \text { presented their technique for intraop display of brain shift \& its effects on fiber tracts. Preop DWI data were } \\
\text { fused w/ anatomic T1-weighted MRI data. Intraoperatively, a single-rack 3D US NN system, displaying simultaneously } \\
\text { the MRI scan \& the corresponding US image, was used for navigation, manual definition of fixed \& potentially shifting US } \\
\text { landmarks near the fiber tract, \& sequential image updating at different steps of resection. The result was time-dependent } \\
\text { brain shift data. }\end{array}$ \\
\hline 2006 & PET & PET-only scanners were no longer obtainable \& replaced world-wide by PET-CT. ${ }^{86}$ \\
\hline 2007 & NN & $\begin{array}{l}\text { Rasmussen et al. } .^{71} \text { described functional NN combined w/ intraop 3D US. The authors developed protocol for integration of } \\
\text { fMRI \& DTI data in a US-based NN system. A coregistration method for automatic brain shift correction of preop MR data } \\
\text { using intraop 3D US was demonstrated. }\end{array}$ \\
\hline
\end{tabular}

* BOLD = blood oxygenation level-dependent; DTI = diffusion tensor imaging; DW-MRI = DW MR image; FBS = frame-based stereotaxy; MRA = MR angiography; MRS = MR spectroscopy; MRV = MR venography; NN = neuronavigation; NMR = nuclear MR; PW-MRI = perfusion-weighted MR imaging; US = ultrasonography.

Attempts to construct mechanical devices for localization of intracranial structures began at the end of 19th century. In the absence of any imaging techniques at that time, this task was doomed to failure. The subsequent introduction of radiography, CT, MR imaging, SPECT, PET, ultrasonography, and other technological advancements led to the development of frame-based stereotaxy and its evolution into neuronavigation.

\section{History of Frame-Based Stereotaxy}

In 1890, Zernov, ${ }^{96}$ a Russian anatomist, described the "encephalometer"-an arc-based skull-fixed device for intracranial localization based on superficial landmarks and polar coordinates - that was designed for anatomical operations on the human brain. This device was actually used on at least 3 occasions. 


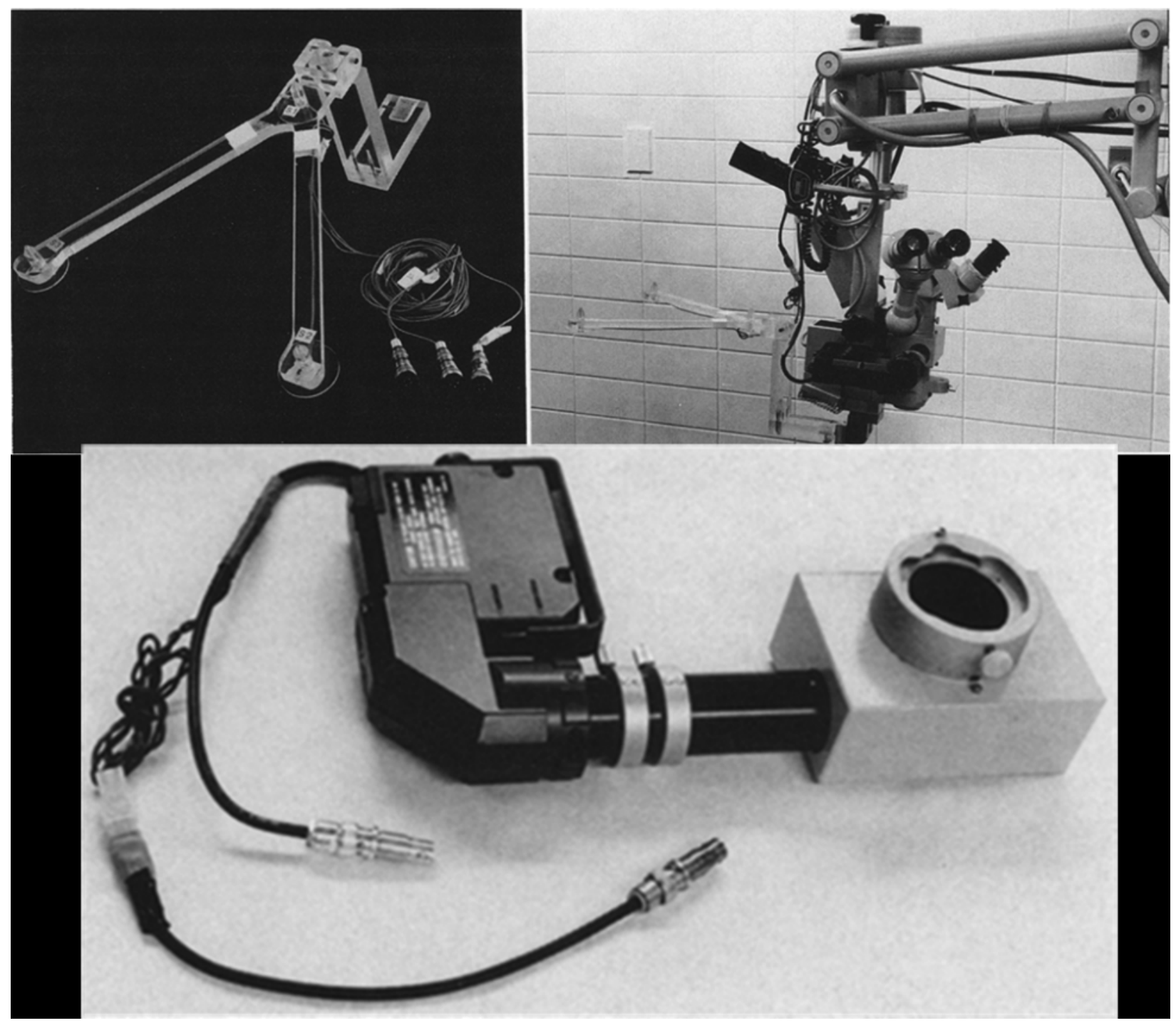

FIG. 1. Photographs showing components of the frameless stereotaxic system. Upper Left: The Plexiglas bracket with a nonlinear array of 3 spark gaps. This component of the acoustic localization system attaches to the operating microscope. Upper Right: The adapted operating microscope with spark gap bracket and optical projection system attached. Lower: The optical projection system. A miniature cathode ray tube is attached to a beam-splitting assembly that can be inserted into the operating microscope between the magnification changer and the binocular. Reproduced with permission from Roberts et al: A frameless stereotaxic integration of computerized tomographic imaging and the operating microscope. J Neurosurg 65:545-549, 1986.

In 1891, Zernov's pupil Altuchow studied the basal ganglia with the encephalometer. ${ }^{3}$

In 1908, Sir Victor Alexander Haden Horsley ${ }^{41}$ (Horsley's first 2 names were given him by Queen Victoria), a neurophysiologist and neurosurgeon, and Robert Henry Clarke, a mathematician, engineer, and inventor, defined stereotactic calculation based on a coordinate system. They created a frame fixed to the skull, which could accurately locate any intracranial point in 3D and guide the introduction of an electrode into the dentate nucleus of monkeys. The stereotactic frame used skull landmarks for intracranial targeting, so an atlas of brain anatomy coordinated to those external landmarks was also created. The frame was used only for experimental studies. With the specially devised apparatus, Horsley and Clarke pro- duced a minimal electrolytic lesion of a cerebellar nucleus without involving the cerebellar cortex. This was the first use of electrolysis in experimental physiology. Horsley and Clarke concluded that the cerebellar cortex is practically inexcitable, but this has been disproved by subsequent investigation with the use of a stronger electrical current. Clarke suggested to Horsley that the stereotactic method could be useful in neurosurgical procedures in human patients. However Horsley laughed at this idea, and it ended their fellowship. Nevertheless, Clarke submitted a patent application for a human stereotactic instrument in 1912. Extension of the technique for use in patients was restricted, however, because of the immense variability between cerebral structures and skull landmarks in humans. Sir Victor Horsley was knighted in 1902 for his 


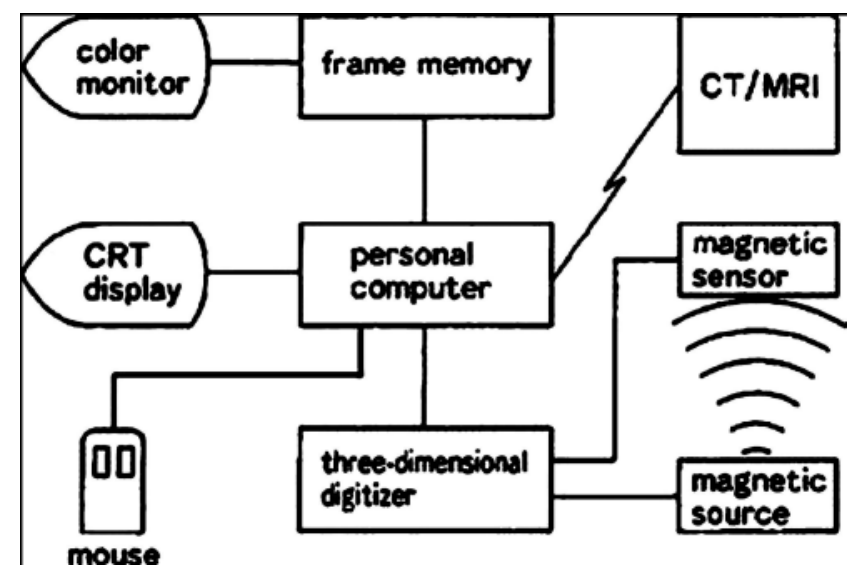

FIG. 2. Block diagram of the frameless, armless navigational system based on magnetic sources introduced by Kato et al. Computed tomography scans or MR images were entered into the system as digital data and displayed on the color monitor. The spatial information of the probe in the operative field was sampled with a magnetic field sensor and was translated by the computer to display a cursor on the corresponding location of the images. CRT = cathode ray tube. Reproduced with permission from Kato et al: A frameless, armless navigational system for computer-assisted neurosurgery. Technical note. J Neurosurg 74:845-849, 1991.

many contributions to medicine, several years before the introduction of his best known innovation, the HorsleyClarke apparatus (developed in 1908). Besides being a pioneer of neurosurgery, Horsley was also a champion of many social causes, including the temperance movement, women's suffrage, medical reform, and free health care for the working class. He died of heatstroke at the age of 59 years during the First World War as a volunteer surgeon in Iraq.

In 1918, Walter Dandy ${ }^{19}$ accidentally invented ventriculography after performing radiography in a patient with an open, penetrating head injury, and observing the ventricles filled with air. Ventriculography became a fundamental technique for calculating stereotactic targets in the basal ganglia and thalamus because of their definite and stable relationship to the third ventricle topography.

In 1933, Kirschner ${ }^{46}$ was the first surgeon to apply frame-based stereotaxy to human patients. He punctured the skull base's foramen ovale to treat idiopathic trigeminal neuralgia. The individual variations in the intracranial structures in humans as opposed to animals and the absence of imaging techniques to visualize these variations, however, limited the stereotactic calculation of deep brain targets.

In 1947, the doctors Ernest Spiegel (a conservative Austrian-trained experimental neurologist who escaped to the US from Nazi occupation during World War II) and his student Henry Wycis (a colorful but talented neurosurgeon $)^{80}$ introduced the first framed stereotactic tool with 3D targeting using internal brain anatomy. Their apparatus-called the "stereoencephalotome"-was similar to Horsley and Clarke's prototype. Its design included a plaster cap adaptable to each individual patient. A head ring was suspended from the adaptable cap, and an electrode carrier was fixed to the head ring. Spiegel and

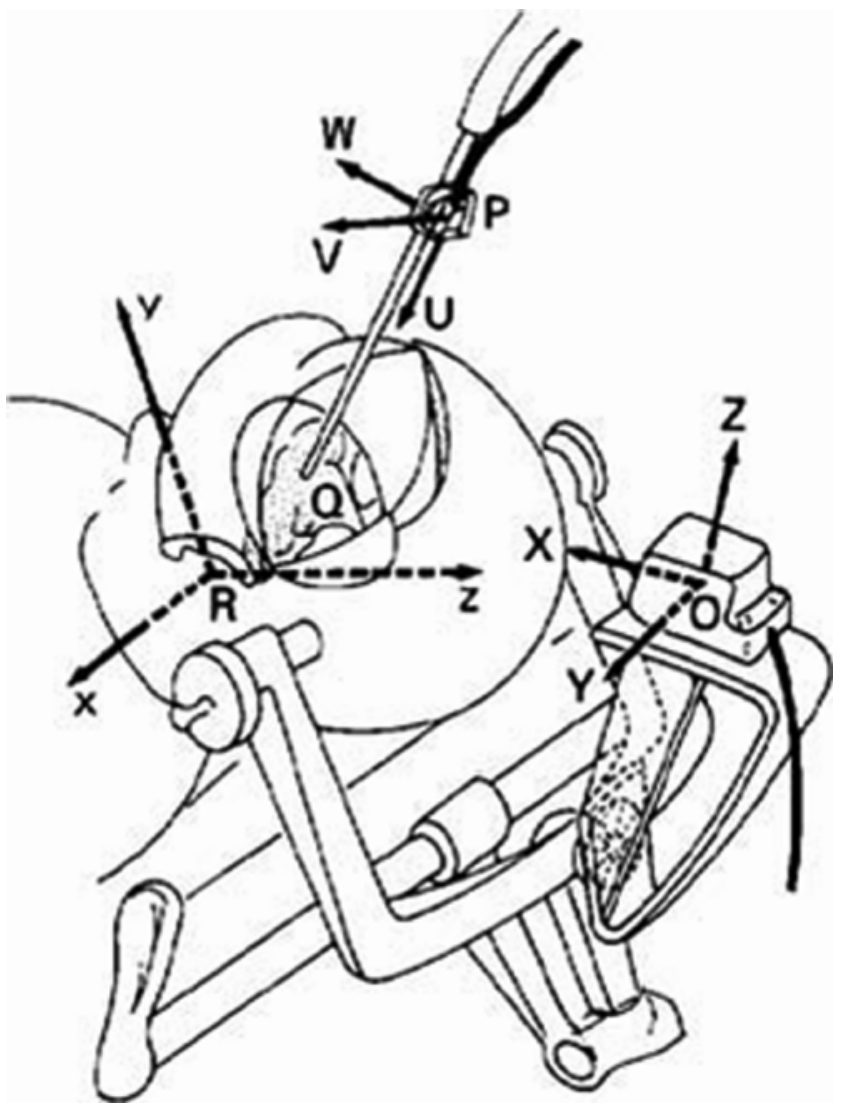

FIG. 3. Schematic drawing of the surgical setup with the computerassisted neurosurgical navigational system. Both the patient's head and the magnetic source $(0)$ were fixed with a Mayfield skull clamp. The position and orientation angles of the sensor $(P)$ were measured with the 3D digitizer with respect to the source reference frame $(O: X, Y$, $Z)$ by the magnetic field modulation method. The position of the probe tip $(Q)$ was then calculated, translated with respect to the CT reference frame (R: $x, y, z)$, and displayed on the CT or MR images with a cursor. Reproduced with permission from Kato et al: A frameless, armless navigational system for computer-assisted neurosurgery. Technical note. $\mathbf{J}$ Neurosurg 74:845-849, 1991.

Wycis' unique contribution was the idea of relating anatomical targets to internal brain landmarks-hence the name "stereoencephalotomy." The frame was attached to a patient's head, and orthogonal pneumoencepholograms were used to visualize the key internal brain landmarks. The therapeutic targets were identified using an accompanying atlas. Spiegel and Wycis performed the first stereotactic thalamotomy in humans using the pineal body or commissura posterior as an internal individual reference system. They also suggested the application of stereotaxy for the treatment of intractable pain, movement disorders, and cystic tumors. Since the advent of the Spiegel-Wycis technique, frames and atlases have evolved. Functional operations with similar frames and techniques have been introduced by various authors.

In 1949, the electrophysiologist Lars Leksell ${ }^{55}$ in Stockholm developed his own arc-centered stereotactic apparatus for intracranial surgery. It was the first stereotactic device with transcutaneous pin fixation to the skull. This instrument used a new concept: the arc quadrant, and 
Neuronavigation: past, present, and future

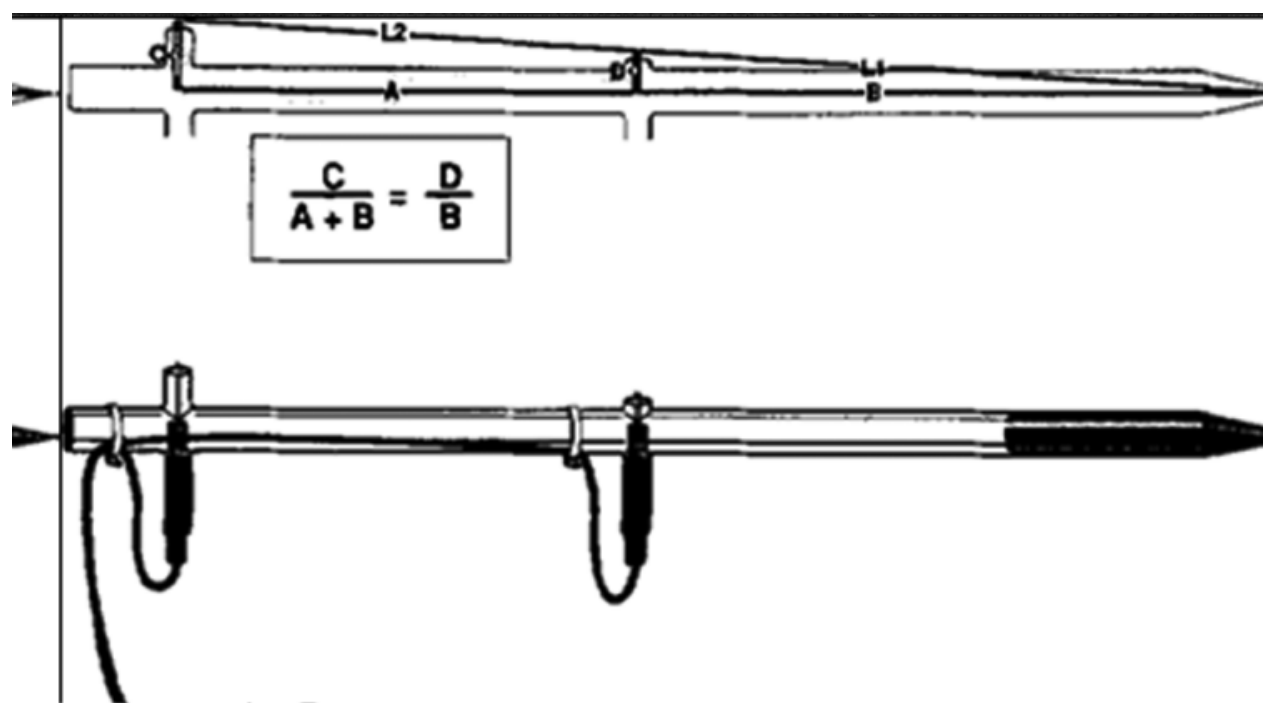

FIG. 4. Diagram of a prototype armless localizing device for frameless stereotaxy using ultrasonic 3D digitization. This technique may be modified for use with other surgical instruments. Lettering refers only to the line segments shown. Reproduced with permission from Barnett et al: Intraoperative localization using an armless, frameless stereotactic wand. Technical note. $\mathbf{J}$ Neurosurg 78:510-514, 1993.

was different in principle from the work of Spiegel and Wycis: instead of using the Cartesian coordinate frame, it used polar coordinates. Leksell's apparatus consisted of a fixation device for the patient's skull and a movable arc quadrant attached to the fixation device. The arc quadrant was moved so that the arc center was positioned at the desired intracranial target point. The stereotactic localization system was also used by Leksell in his next invention, a device for radiosurgery of the brain.

The same year, Jean Talairach ${ }^{83}$ in Paris described a grid-based stereotactic instrument and introduced the concept of layering angiography on radiographs in the development of surgical stereotactic maps. Radiographs obtained with the fixed grid demonstrated overlaying of the grid holes over a positive contrast ventriculogram. Talairach also introduced the concept of teleradiography, in which precise measurements could be made directly from intraoperatively obtained radiographs. The Talairach frame could be removed and fixed again at precisely the same position of the patient's head. Thus images obtained in one operation could be used to guide subsequent procedures.

In 1952, Riechert and Wolff ${ }^{74}$ in Germany reported on their own stereotactic device for functional procedures, which was similar to that described by Kirschner. This apparatus included an aiming bow attached to a circular base ring for fixation to the patient's head. The aiming bow was transposed to a phantom base ring on which the surgeon set up his target coordinates on a simulator. The instrument was used in many tumor and functional stereotactic procedures.

In the mid-1960s, neurosurgeon Edwin Todd and biomedical engineer Trent Wells invented the Todd-Wells Stereotactic Unit, which was the first widely produced stereotactic frame, used at many clinics worldwide. ${ }^{7}$

In 1979, Russell Brown, a medical student, neurosurgeon Theodore Roberts, and the aforementioned Trent
Wells developed a stereotactic instrument with capabilities to translate CT data into an operational setting-the Brown-Roberts-Wells stereotactic system.6,39,90 Subsequent developments led to the introduction of the flexible Cosman-Roberts-Wells stereotactic system.

In 1987, Young ${ }^{93}$ reported on a stereotactic system based on a robotics model. The robotic CT stereotactic system was mounted in a special operating suite, which contained a CT scanner and adjacent computer room. Stereotactic coordinates were derived from CT data obtained intraoperatively and transferred by computer link to the robotic stereotactic system. The robotic arm was driven into place to align it with predetermined coordinates.

During the 1980s, as stated by Apuzzo and Sabshin ${ }^{7}$ 'the computer became a 'neurosurgical tool,' and elements of stereotaxy became part of the repertoire of the general neurosurgeon."

In 1992, Benabid et al. ${ }^{11}$ described the development of a 6-axis stereotactic robot that had been linked to a stereotactic frame for routine stereotactic procedures, including placement of electrodes for deep brain stimulation. Robot software allowed the positioning of a probe holder to reach a given target.

Frame-based stereotaxy, even with its high application accuracy, limits the range of surgical approaches, does not allow for integration of more than 1 type of structural or functional imaging data, and causes preoperative patient discomfort.

\section{History and Present Status of Neuronavigation}

In the 1980s, progress in the fields of imaging technology, electronics, computers, and robot technology was the background for the development of more sophisticated devices for stereotactic surgery. ${ }^{35}$

In 1986 , Roberts and colleagues ${ }^{75}$ developed the con- 


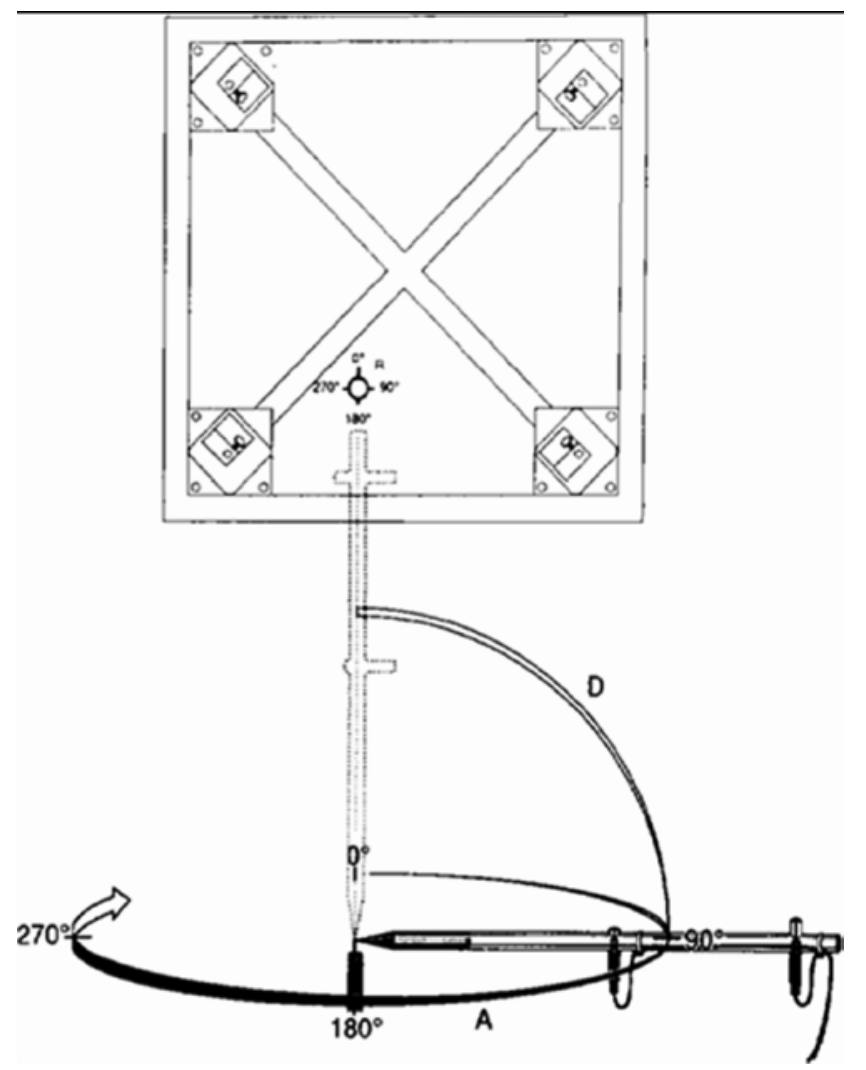

FIG. 5. Schema for determining the effects on system accuracy of the wand position with respect to the microphone array. $A=$ azimuth; $D$ = declination; $\mathrm{R}$ = rotation. Reproduced with permission from Barnett et al: Intraoperative localization using an armless, frameless stereotactic wand. Technical note. J Neurosurg 78:510-514, 1993.

cept of frameless stereotaxy or neuronavigation. Roberts' device was composed of an operating microscope on a solenoid floating stand, which was tracked in 3D by a sonic digitizer (Fig. 1). The microscope adapted for navigated surgery was equipped with ultrasound-emitting sources and microphones arranged outside the operating field. The microphone data were processed by a computer, which calculated the microscope's position in space. The predefined target point on CT or MR images could be projected into the microscope ocular and used for intraoperative navigation.

In 1987, Watanabe in Tokyo and Reinhardt in Basel each independently developed multiaxis mechanical measuring arms equipped with potentiometric angular sensors and video equipment for digitizing of the CT scans from conventional films. ${ }^{72,88}$ These arm-based navigation systems were used for neurosurgical procedures.

In 1991, Kato et al. ${ }^{44}$ introduced a frameless, armless navigational system based on magnetic sources. The device included a 3D digitizer, a personal computer, and an image-processing unit (Fig. 2). Applying magnetic field modulation technology, the 3D digitizer determined the spatial position and orientation angles of the probe, triangle-shaped pointer, or suction tube with a small attached magnetic field sensor (Fig. 3). Four fiducial markers on the scalp were used to translate the spatial data of the probe onto the preoperative CT scans or MR images of the patient.

In 1993, Reinhardt et al. ${ }^{73}$ reported on an armless navigation system that used a pointer emitting ultrasound signals. Localization in space was made by measuring the traveling time of sonic waves in air. The applied freehand targeting instruments were light and mechanically simple.

In the same year, Barnet et al. ${ }^{9}$ described a technique of frameless stereotaxy that allowed real-time intraoperative neurosurgical localization. The system was composed of a hand-held probe containing 2 ultrasonic emitters, a microphone array that is rigidly affixed to the operating table in proximity to the surgical field, hardware to control and detect timing of signal production and reception, and a computer workstation with software to calculate and present the location of the probe tip on reconstructed neuroimaging studies (Figs. 4 and 5). Unlike previously reported mechanical or sonic navigational devices, this system was adaptable to a wide array of neurosurgical instruments, allowed free movement of the operating table and conventional patient draping, and had accuracy rivaling that of frame stereotaxy.

In 1993, Zamorano et al. ${ }^{95}$ reported on a neuronavigation device based on optoelectronic measuring principles. Infrared LEDs were applied as emitting sources. Additional intraoperative digitization of the surgical instruments can be achieved by affixing infrared-based digitizers to them.

In 1993, Koivukangas et al. ${ }^{47}$ reported on a computer-assisted neuronavigation system that consisted of a neuronavigator arm with 6 degrees of freedom and highprecision potentiometers to indicate the movement of the joints. Intraoperative ultrasonography helped to verify the accuracy of the neuronavigator and check the results of the procedures.

Soon after these iMR imaging systems were implemented, there was the wish to combine them with neuronavigation.

In 1995 the first neurosurgical procedure was performed in the 0.5-T iMR imaging suite, widely known as the General Electric “double doughnut," with a 56-cmwide vertical gap at the center of the magnet. This system permited 2 neurosurgeons to stand on either side of the patient and perform procedures completely within the bore of the magnet. ${ }^{13}$ An LED-based neuronavigational system was integrated with the iMR imaging unit, which provided neuronavigation within the vertical gap at the center of the magnet. In iMR imaging, the neuronavigational image data set guiding the surgery could be continually assessed by visual inspection of MR imaging scans obtained throughout the course of the procedure at the request of the neurosurgeon. Imaging was performed without moving the patient in and out of the magnet. The "double doughnut" unit combined intraoperative scanning and neuronavigation with surgery within the same space of the operating theater. With the iMR imaging suite, the whole surgical procedure could be performed in 1 room; neither the patient nor the magnet needed to be moved intraoperatively, 2 neurosurgeons could have access to the patient simultaneously, and near real-time images were 


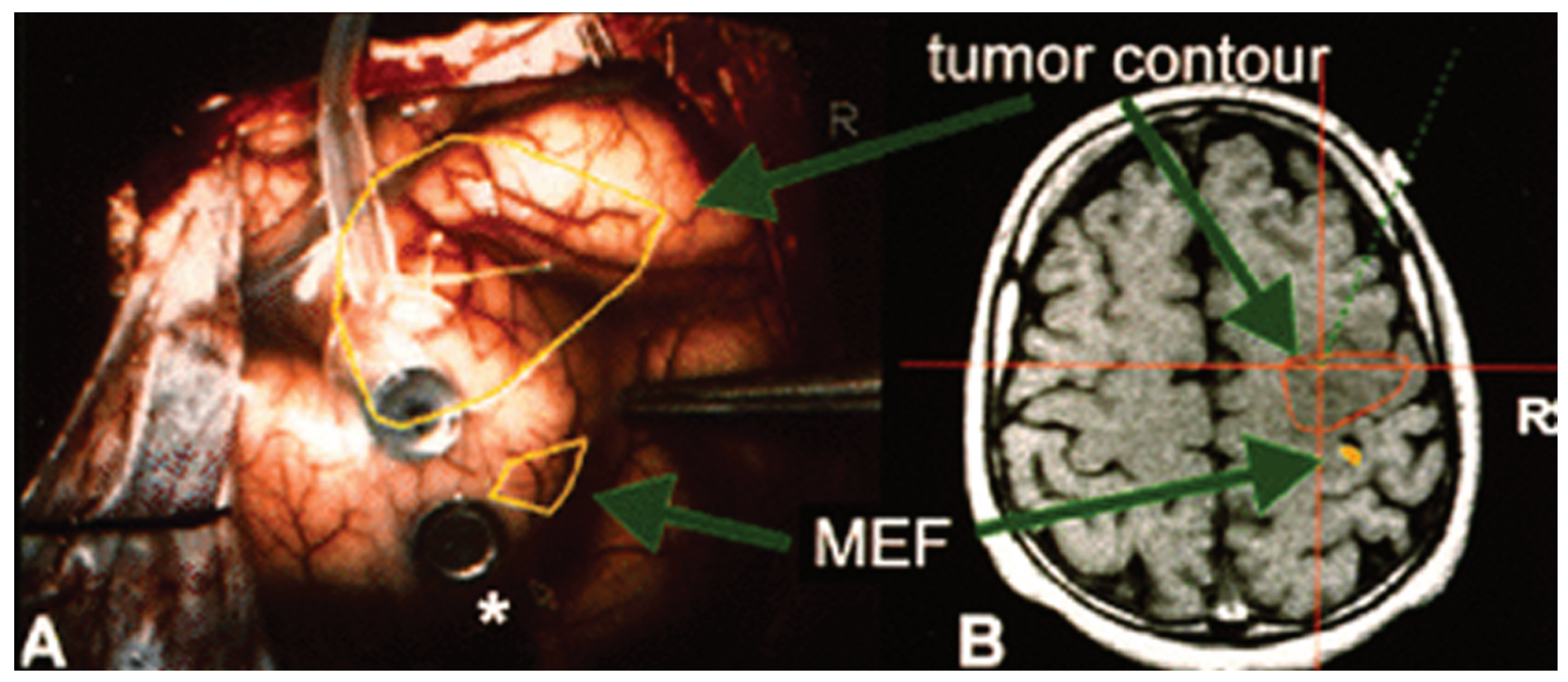

FIG. 6. A: In this patient the motor evoked field (MEF) dipole representing the motor cortex is displayed on the same gyrus as the tumor, which indicates that a resection is not possible. The asterisk represents the sensory evoked field phase reversal and indicates the central sulcus. B: Screenshot of the MR imaging data set as displayed on the workstation, showing the tumor contour and MEF dipole (green triangle in the precentral gyrus). Reproduced with permission from Ganslandt et al: Functional neuronavigation with magnetoencephalography: outcome in 50 patients with lesions around the motor cortex. Neurosurg Focus 6:E5, 1999.

provided. The disadvantages to this system included: a lower image quality compared with the high-field 1.5-T in closed MR suites; the inability to undertake functional, diffusion-perfusion, and spectroscopic studies because of the relatively low magnetic field strength; a limited working space for the surgeons, especially in transsphenoidal surgery; and increased costs because of the use of MRcompatible nonferromagnetic surgical equipment.

In 1997, Tronnier et al.$^{87}$ described iMR imaging for intraoperative update of the neuronavigation data sets. A 0.2-T magnet (Magnetom Open, Siemens AG) inside a special cabin with a radiofrequency-shielded sliding door was installed adjacent to the operating theater. A specially designed patient transport system was used to carry the patient in a fixed position to the magnet and back to the operating room. The operations were performed as routine image-guided microsurgical procedures with different neuronavigational devices. Following the surgeon's judgment regarding the extent of tumor resection, 4-5 fiducial markers were charged with Gd and screwed into the skull around the craniotomy. These markers were registered as intraoperative reference markers with the neuronavigation. The patient was transferred to the scanner covered with a sterile drape, leaving the skin and dura mater open. After the imaging procedure, in case of residual tumor, the 3D data set was sent to the neuronavigation workstation via ethernet, and data processing was performed (in 20-40 minutes) while the patient was being transferred back to the operating theater. The procedure was continued with the new updated navigational data set, reflecting brain shift.

In 1998, Matula et al. ${ }^{61}$ connected a fixed iCT scanner (Philips Tomoscan M) to a LED-based navigation system (Philips EasyGuide system) to provide an integrated solution to the problem of brain shift. The gantry was fixed and the patients were positioned on a specially developed scanner table that permitted movement from a scanning position to the operating position at any time during surgery. The procedure was completed with the updated navigational data. The authors' idea was to work in a closed system where everything was performed in the same room.

The same year, Grunert and colleagues ${ }^{36}$ reported on their concept: to adapt a mobile CT scanner to a neuronavigation system. They integrated the intraoperative mobile Philips Tomoscan M, which has a portable lightweight gantry on 4 wheels and can be moved by a single person, with 1 of the following neuronavigation devices: the Radionics optical tracking system, the Philips EasyGuide system, the Radionics arm-based operating arm system, or the Zeiss microscope-based MKM system. In contrast to the other intraoperative CT devices, the slices were performed by gantry translation and not by CT table movement. The updated CT image data were matched onto the preoperative CT data set.

In their 1999 study in 50 patients with lesions around the motor cortex, Ganslandt et al. ${ }^{32}$ superimposed MEGsource localizations onto 3D MR images, and the image data set was then implemented into a neuronavigation system. The sensorimotor cortex was identified correctly in all patients with the use of MEG (Fig. 6). The authors concluded that this method of incorporating functional data into neuronavigational systems is a promising tool that can be used during more radical surgeries to reduce injury to eloquent brain areas.

In 1999, Nimsky et al. ${ }^{66}$ described functional neuronavigation based on the fusion of $\mathrm{fMR}$ imaging and MEG data with an anatomical 3D MR imaging set by a contour fit. The matched 3D image data set was transferred to the navigation microscope and displayed on the operating 


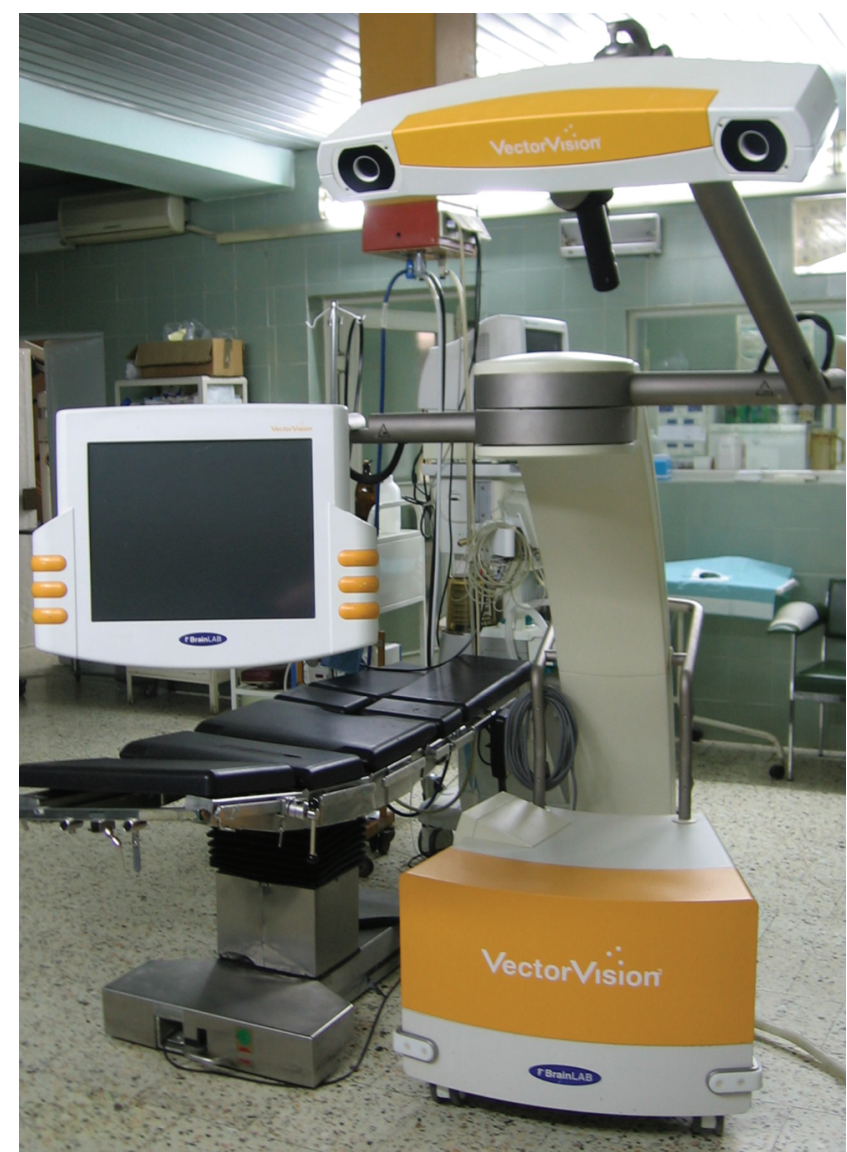

FIG. 7. Photograph of frameless, armless, image-guided neuronavigation system, based on passive reflection of infrared light (VectorVision2, BrainLab).

viewing field during surgery. Additionally, intraoperative recording of somatosensory evoked potentials was performed for verification of the central sulcus. In all 7 cases, the projection of fMR imaging and MEG data allowed easy identification of the central region, which was confirmed by somatosensory evoked potentials.

In 1999, Samset and Hirschberg ${ }^{76}$ described an adaptation of a standard neuronavigation system (OTS Radionics) into a 0.5-T iMR imaging scanner (Signa SP, General Electric Medical Systems). The scanner has a $60-\mathrm{cm}$-wide vertical gap where both imaging and surgery are conducted and in-bore infrared linear cameras and monitors for neuronavigation. The incorporation of intraoperatively updated MR imaging data sets into neuronavigation helps to overcome the challenge of brain shift. Performing surgery within the imaging volume of the iMR scanner eliminates the problems associated with patient or scanner transport during the procedure, and patient immobilization during the procedure obviates the need for reregistration of the patient, because of the fixed camera system in the bore of the iMR system.

In 2000, Gronningsaeter et al. ${ }^{34}$ described the integration of an optical neuronavigation system into an ultrasound scanner. In this way the authors developed a single-rack system (SonoWand, MISON A/S) that enabled the neurosurgeon to perform frameless/armless neuro- navigation using preoperative MR or CT images as well as intraoperative $3 \mathrm{D}$ ultrasonography data.

In 2001, Braun et al..$^{14}$ reported on the first case of direct integration of fMR imaging and PET data into cranial neuronavigation (Zeiss MKM system navigation microscope, Carl Zeiss Co.), which was performed in a patient with a left precentral oligodendroglioma. The correct fMR imaging localization of the precentral gyrus was intraoperatively verified by cortical somatosensory evoked potential monitoring. Although the tumor was not clearly defined on MR images, $\left[{ }^{11} \mathrm{C}\right]$ methionine PET scans demonstrated a clear tumor border, enabling the authors to achieve gross-total tumor removal without postoperative functional deficits.

In 2001, Nimsky et al. ${ }^{65}$ reported a new concept of anatomical and functional microscope-based neuronavigation combined with intraoperative MR imaging by positioning a navigation microscope within the fringe field of the MR imaging scanner. Each patient was laid directly on the table of the iMR scanner (0.2-T Magnetom Open), which was placed in a radiofrequency-shielded operating theater. The patient's head was fixed in an MR imagingcompatible ceramic head holder. The NC-4 navigation microscope (Zeiss) with a camera for tracking the microscope movements was positioned at a distance of $\sim 1.5 \mathrm{~m}$ in the $5-\mathrm{G}$ perimeter. The navigation and iMR imaging workstations were placed outside the radiofrequency-shielded operating room. The margins of the tumor, the predefined surgical approach, and the functional data were displayed in the surgeon's microscope viewing field. The neuronavigation update added approximately an additional 15 minutes to operating time, including the time for image transfer, segmentation of suspected remaining tumor, defining the surgical approach, and rereferencing. The advantages of the described iMR imaging system included: increased access to the patient (the surgery is performed in an ordinary operating room) in contrast to the ergonomic restrictions of the earlier "doubledoughnut" system; elimination of needless cumbersome and time-consuming patient transport; ability to use MR imaging-incompatible surgical instruments, thus obviating the need for a full set of MR imaging-compatible instruments, which could be of inferior quality; expense; and restricted in available range. The disadvantages of this low-field 0.2-T imager included: less tissue resolution; inability to undertake functional, diffusion-perfusion, and spectroscopic studies because of its relatively low magnetic field strength; the requirement for intraoperative transport of the patient into and out of the magnet, thus increasing the time of surgery; and the potential risk of intraoperative infection.

In 2001, Zaaroor et al ${ }^{94}$ reported on a novel magnetic technology for intraoperative intracranial frameless neuronavigation. The Magellan electromagnetic neuronavigation system (Biosense Webster) was developed to provide real-time tracking of the distal tips of flexible catheters, steerable endoscopes, and other surgical instruments using ultralow electromagnetic fields and a novel miniature position sensor for image-correlated intraoperative navigation and mapping applications. The system provided precise lesion localization without limiting the 


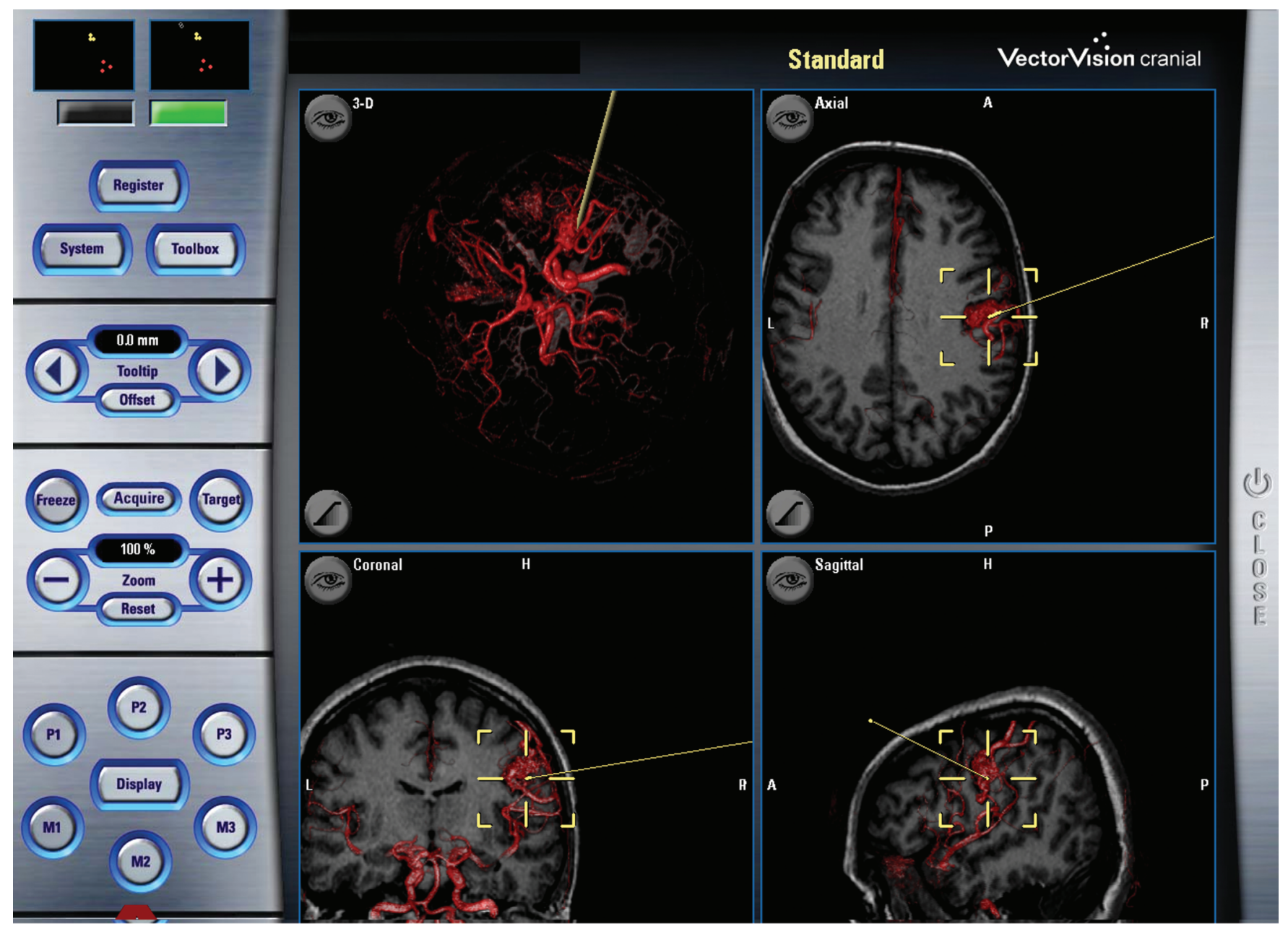

FIG. 8. Screenshot showing the intraoperative application of LED-based neuronavigation in a patient with right frontoparietal cerebral arteriovenous malformation. Preoperative fusion of MR imaging and MR angiography images was performed. Yellow lines represent the pointing instrument.

line of vision, the mobility of the surgeon, or the flexibility of instruments.

In 2002, Zimmermann et al. ${ }^{98}$ described their preliminary experience with robot-assisted neuronavigated neuroendoscopy in 3 patients. The Evolution 1 precision robot (Universal Robot Systems), especially designed for neurosurgery, was used simultaneously with the VectorVision2 neuronavigation system (BrainLab). The time for the registration process and for the robot setup decreased from 1 hour in the first case to half an hour in the last case. The duration of the endoscopic part of the surgical procedure ranged from 17 to 65 minutes. No device- or surgery-related deaths or complications were reported in their series. Based on their limited experience, the authors concluded that the advantage of using the Evolution 1 robot as a holding and positioning device for the neuroendoscope was the possibility of performing precise, smooth, and slow motions in critical regions. Neuronavigation increased the accuracy and safety of robot-assisted endoscopic procedures, supplying visual feedback regarding the intracranial position of the endoscope. The main disadvantage of the described robot was that it could not be used for endoscopic procedures requiring a larger range of motion.

In 2003, Nakao et al ${ }^{64}$ reported on their technique of updating neuronavigational data with a mobile CT scanner used to acquire intraoperative images at a 2-mm-slice thickness. Several skull-fixed titanium screws were used as reference points for the intraoperative registration of the neuronavigation updating. Following the processing of the intraoperatively obtained CT image data from the workstation of the neuronavigation system, the navigational data were updated by registering the mentioned reference points. Under the guidance of the fully updated neuronavigation, the residual lesions were defined and further resected. The authors concluded that this technique, compared with iMR imaging, could be performed in an ordinary operating room without requiring special surgical instruments.

In 2003, Lindseth et al. ${ }^{57}$ reported an image fusion between preoperative MR imaging and intraoperative 3D ultrasonography in an ultrasonography-based neuronavigation system (SonoWand, MISON A/S) for visualizing brain shift and improving intraoperative interpretation. 


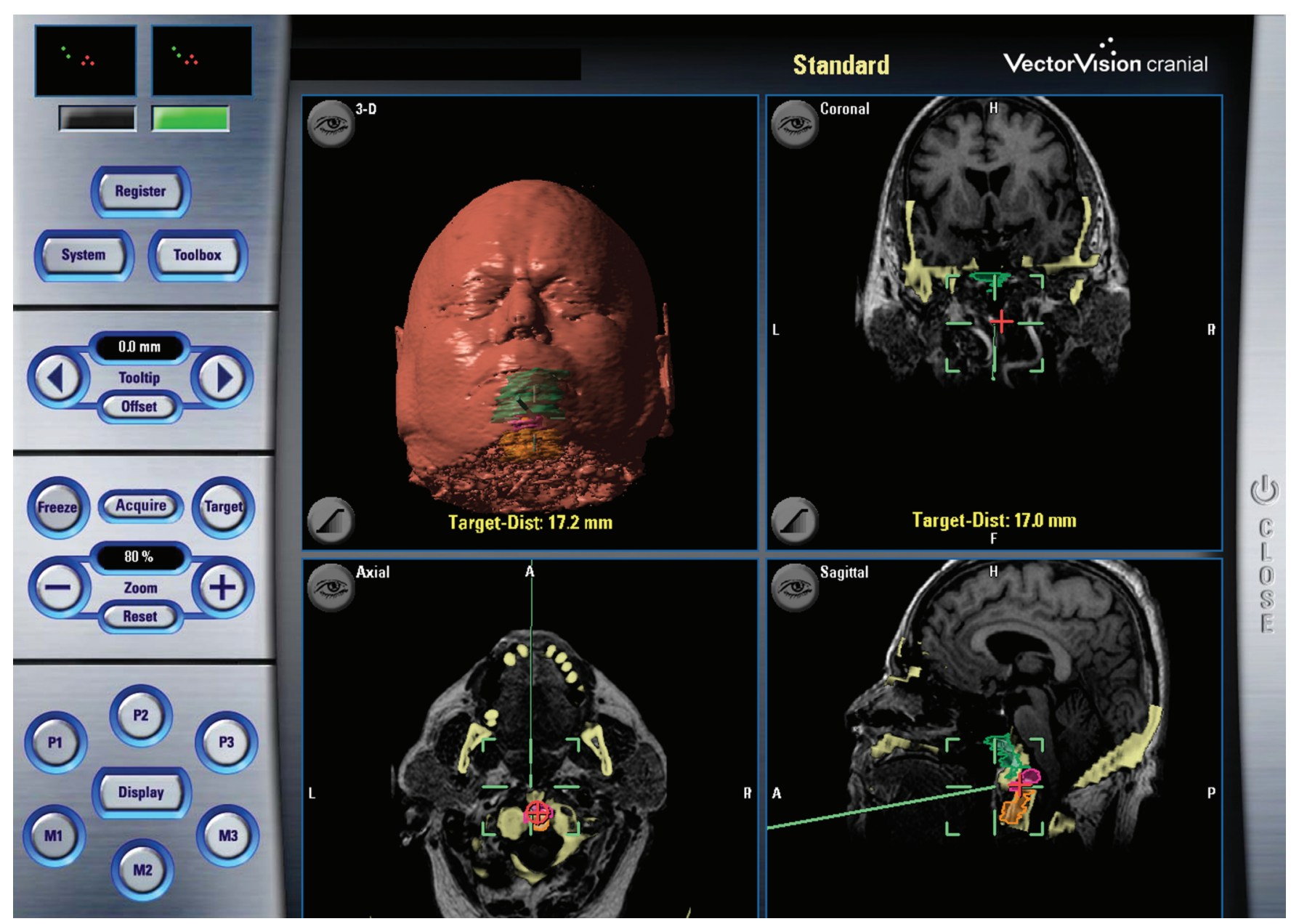

FIG. 9. Screenshot showing the intraoperative application of LED-based neuronavigation in a patient with a chordoma engaging the clivus and C-1 and C-2 vertebrae. For better visualization of bone and soft tissues, MR images and CT data sets were fused preoperatively.

The authors evaluated the integration of pre- and intraoperative data for surgical planning, guidance, and resection control as a useful means of improving the quality of the surgical procedure and, hence, patient outcome.

In 2005 , Coenen et al..$^{15}$ presented their technique for intraoperative display of brain shift and its effects on fiber tracts. The technique was performed in 3 patients with intracranial lesions in contact with important fiber tracts. Preoperative DW imaging data were fused with anatomical T1-weighted MR imaging data. Intraoperatively, a single-rack 3D ultrasonography neuronavigation system, which displayed the MR image and corresponding sonogram simultaneously, was used for navigation, manual definition of fixed and potentially shifting ultrasound landmarks near the fiber tract, and sequential image updating during the different steps of resection. The result was time-dependent brain shift data. The lesions were removed without complications. Postoperative DW imaging confirmed the predicted fiber tract deformation.

In 2007, Rasmussen et al. ${ }^{71}$ described functional neuronavigation combined with intraoperative 3D ultrasonography. The authors developed a protocol for integration of fMR and DT imaging data in an ultrasonogra- phy-based neuronavigation system (SonoWand, MISON A/S). A coregistration method for automatic brain shift correction of preoperative MR data using intraoperative 3D ultrasonography was demonstrated. Intraoperative ultrasonography volumes were acquired as needed during surgery, and the multimodal data were used for guidance and resection control. The surgeons reported that the integration of fMR and DT imaging data in the neuronavigation system represented valuable additional information presented in a more user-friendly and efficient way compared with the traditional display on a separated monitor. The automatic ultrasonography-based updates of the preoperative MR imaging data were valuable for surgical planning and guidance.

Because no frame is attached to the patient's head that could interfere with the surgical approach, neuronavigation techniques have broadened the range of possible surgical approaches and opened logistical advantages in terms of scheduling diagnostic studies, in that imaging studies need not necessarily be acquired the same day as surgery (Figs. 7-12). Neuronavigation allows the fusion of $>1$ structural and/or functional imaging data sets for planning, virtual simulation, and optimization of surgi- 


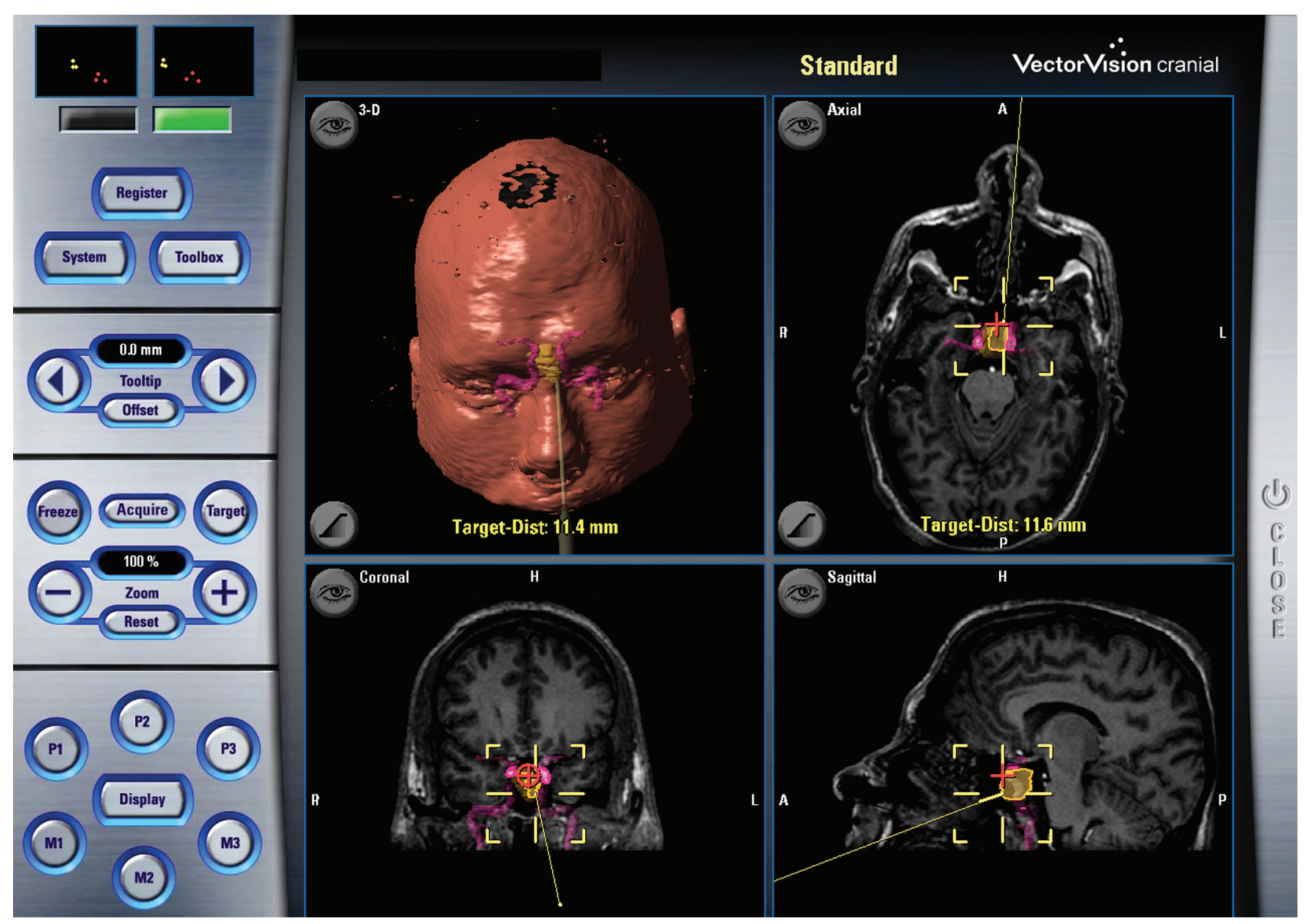

FIG. 10. Screenshot showing the intraoperative application of LED-based neuronavigation in a patient undergoing repeated operation for a pituitary adenoma. The tumor is outlined in yellow and the internal carotid arteries in pink. The red cross is the targeted anterior border of the tumor, most remote of the carotid arteries.

cal procedures. Neuronavigation supplies intraoperative orientation, localization, and guidance with a high level of accuracy and precision. Thus, neuronavigation elevates the neurosurgeon's confidence and reduces the risks for the patient. Neuronavigation acts as a high-tech intraoperative neurovascular protection. The main disadvantage of neuronavigation is the brain shift problem, which has several possible solutions (already discussed).

Neurosurgery currently relies on navigation more than any other specialty. The fact is obvious even from the use of the term neuronavigation, which is in common use in the literature, in contrast to terms like orthonavigation (for orthopedic surgery), which do not actually exist. Presumably, the particular features of the brain (complex anatomy and functional distribution together with vulnerability and lack of regenerative possibilities) impose the requirements for perfect orientation, extreme precision, and minimal invasiveness of neurosurgical procedures. Neuronavigation represents a crucial step forward in this direction and is therefore widely applied to neurosurgical procedures.

Neurosurgical procedures have been compared with sailing $;{ }^{7}$ however, I believe that it is more correct to compare it with space flight: every neuron is a star, every fasciculus is the Milky Way, every brain lobe is a galaxy, and the brain itself is the universe with its specific dynamics. Neuronavigation functions as a space guide that can potentially supply multimodal structural, functional, and chemical information. In our everyday space missions as neurosurgeons, neuronavigation is not obligatory; however, there are not any meaningful arguments against its clinical application.

The term astronaut derives from the Greek words "ástron," meaning star, and "nautes," meaning sailor. Navigated neurosurgery is transforming to "neuronautics," and neurosurgeons to "neuronauts." The growing distribution and application of neuronavigation inevitably necessitates close cooperation between these neuronauts and engineers, software specialists, and other technology professionals connected with the development of the software and hardware.

\section{The Future of Neuronavigation}

Current intraoperative imaging modalities include 


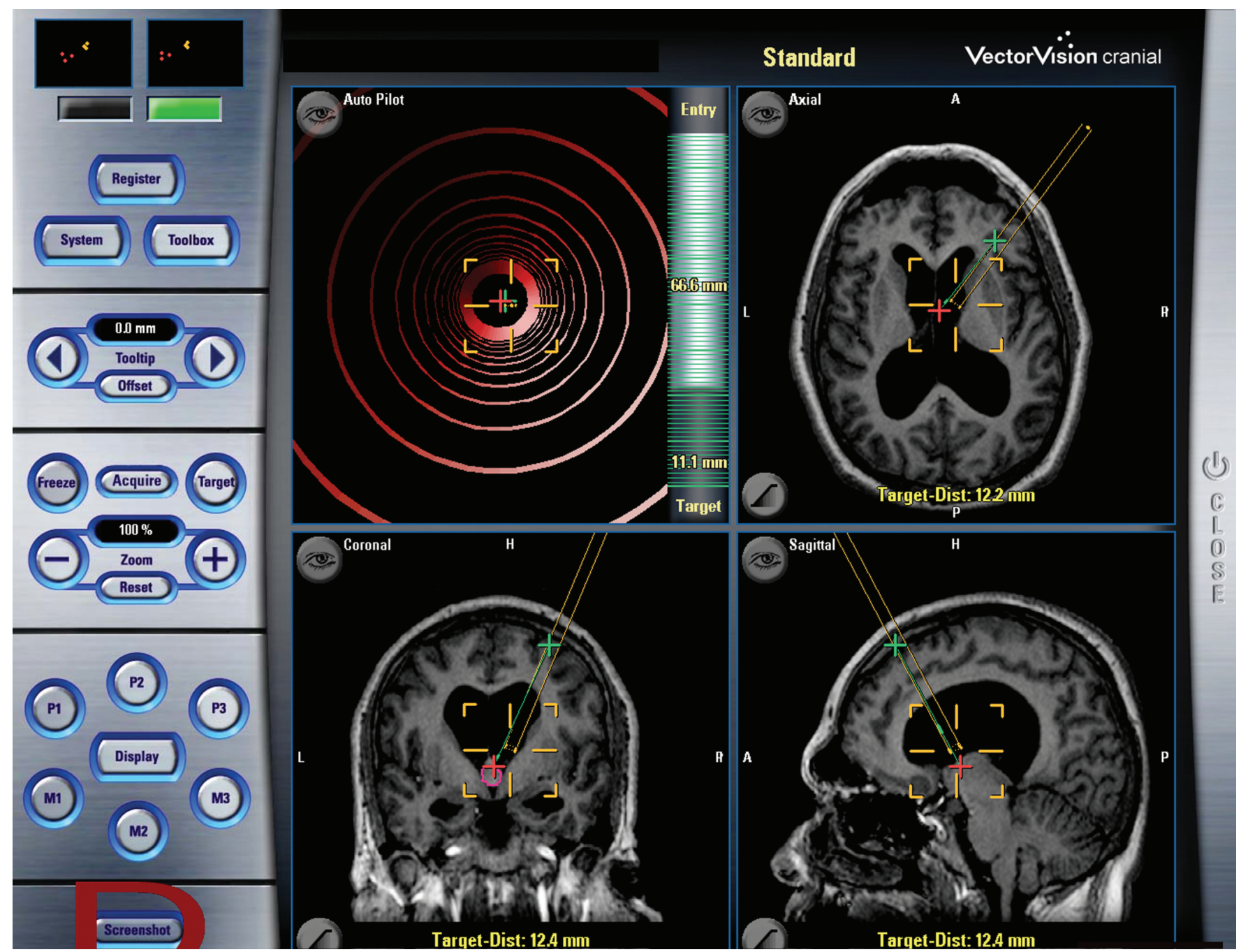

FIG. 11. Screenshot showing the intraoperative application of LED-based neuronavigation in a patient with a colloid cyst. The colloid cyst is outlined in pink, the entry point is marked with a green cross, and the foramen of Monro with a red cross. Parallel yellow lines represent the endoscope shaft. In this case the "auto pilot function" was applied.

radiography, x-ray fluoroscopy, ultrasonography, and CT and MR imaging. Radiography and x-ray fluoroscopy supply only 2D images, and thus have limited application in neuronavigation. ${ }^{79}$ Of the other modalities, MR imaging is the only technique that can provide functional data in addition to structural and anatomical information. With the incorporation of multimodality data sets with structural and functional information, image-guided neurosurgery has evolved into information-guided surgery.

\section{Neuronavigation and Intraoperative $C T$}

In the future, integration of neuronavigation and iCT will not be the leading direction of development of image-guided technology because of the radiation burden to the patients. The advantage of the iCT-based technology compared with iMR imaging is the simplicity of the solution combined with sufficient image quality. If iMR imaging is used, then either the operating theater and all its instruments must be made MR imaging compatible or the patient must be transferred intraoperatively inside a special cabin with a radiofrequency-shielded sliding door, installed adjacent to the operating room or to be rotated in the 5-G perimeter of iMR imaging. The combination of iCT and iMR imaging would be extremely useful in skull base neurosurgery.

\section{Neuronavigation and Intraoperative MR Imaging}

The overlay of functional, diffusion, and perfusion data would constitute a virtual reality view of the brain, and continuous updating of this image would guide the neurosurgeon perfectly with the least possible margin of error in localizing, targeting, and reevaluating the lesion and surrounding tissue intraoperatively. The usefulness and effectiveness of these supplementary modalities still need to be tested in larger series before their standardization. Imaging modalities that use parameters based on the metabolic, diffusion, and perfusion characteristics of neural tissue (fMR, DW, MR angiography, MR venography, 


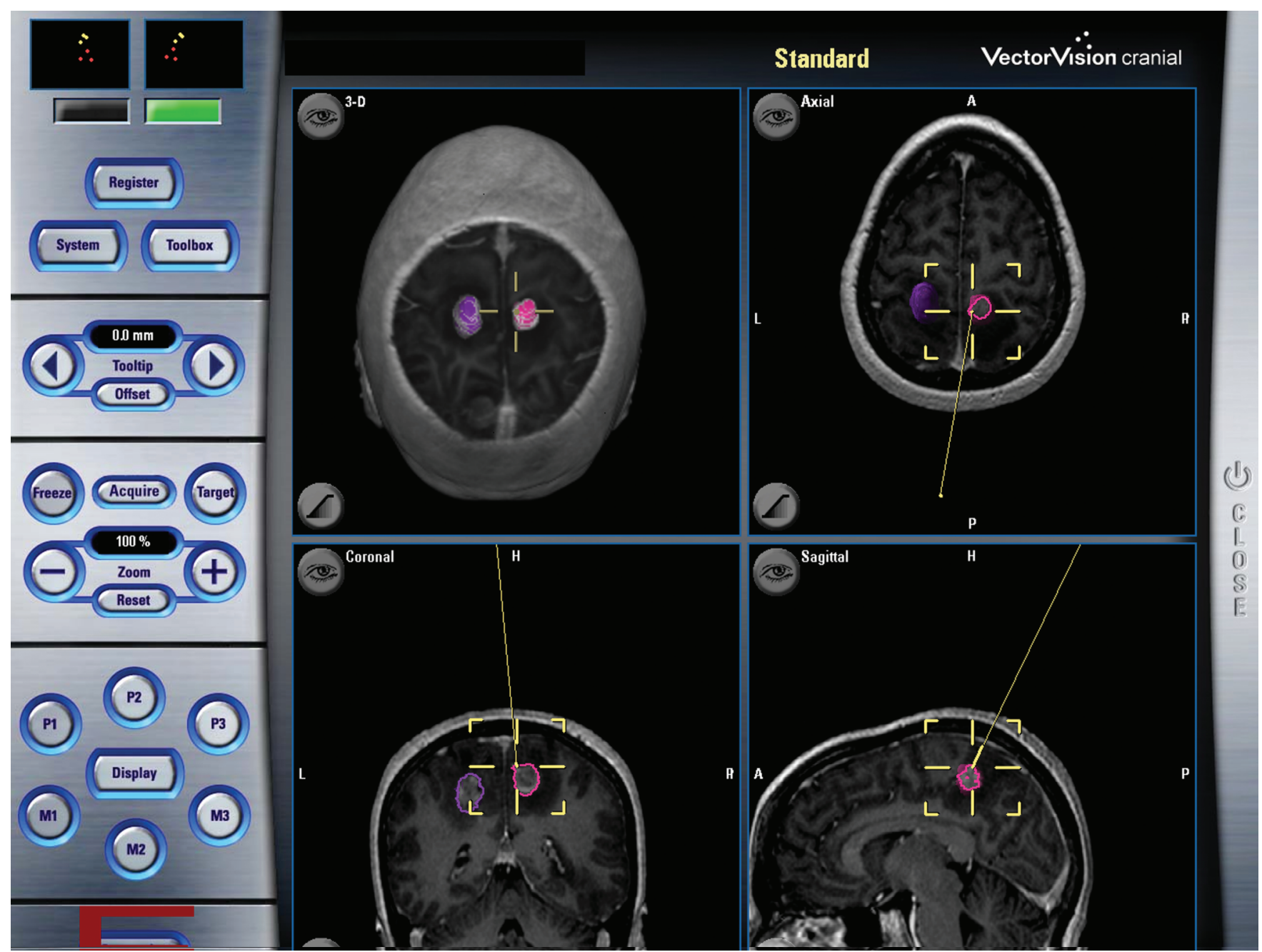

FIG. 12. Screenshot showing the intraoperative application of LED-based neuronavigation in a patient with 2 metastatic tumors (outlined in purple and pink), which were removed simultaneously in a single procedure.

diffusion tensor imaging, and MR imaging spectroscopy) necessitate higher field systems. In the future high-field iMR imaging systems will probably prevail over lowfield systems because they provide functional data, more refined anatomical data, increased signal-to-noise ratio, and higher spatial and contrast resolution. ${ }^{2}$ Most likely, advancements in neuronavigator and MR scanner computer system software would make real-time, intraoperative MR imaging scans available.

\section{Neuronavigation and Intraoperative SPECT and PET}

Both SPECT and PET imaging techniques require radionuclides with their subsequent concerns, expenditures, and radiation hazards. At present, their introduction into the operating room is actually impossible and not cost-effective. Future technological decisions will probably prevail over these obstacles and will allow their real intraoperative integration with neuronavigation.

\section{Neuronavigation and Intraoperative Ultrasonography}

Ultrasonography provides real-time imaging with- out a radiation burden to the patient. Intraoperative ultrasonography does not entail any special requirements on the neurosurgical armamentarium or the environment of the operating theater. Ultrasonographic devices are significantly cheaper than iCT and especially iMR imaging. Intraoperative ultrasonography has been successfully integrated into neuronavigation systems, providing the potential for brain shift evaluation and correction. It is therefore easy to suppose that intraoperative ultrasonography has its place in the neuronavigation of the future.

Microscanning is an exciting and quite promising aspect of ultrasonography. It is essentially the same process as traditional ultrasonographic body scanning, but at higher ultrasonic frequencies. ${ }^{89}$ The ability of microscanning to image thick histological specimens rapidly in 3D, without the need for staining or sectioning, will provide previously inaccessible information about the structure of normal and pathological tissues in the $10-100 \mathrm{~mm}$ resolution range. This may have practical application in the operating theater for in vivo investigations. Another potentially important application, as described by Wells, ${ }^{89}$ is in image-guided trackless microintervention; for example, 
it may be possible for gene transfection of individually targeted cells to be achieved by delivering localized, high intensity ultrasound at the beam focus.

\section{Neuronavigation and Robotics}

Robots are devices invented to complete actions automatically with the ultimate degree of mechanical precision. Robots are extremely useful for the performance of repetitive, monotonous, or tiring tasks. ${ }^{89}$ The use of robots perfectly complements the idea of the neuronavigation. ${ }^{2,98}$ In the near future, robots probably will become integral to neurosurgical treatment. Robots integrated with neuronavigation and equipped with a specially designed artificial intellect will be the neurosurgeons of the future, and telerobotics may enable the remote performance of neurosurgical procedures at distant locations.

\section{Conclusions}

The neuronavigation of the future will be cost-effective, intuitive, ergonomic, user friendly, accurate, and precise, with possibilities for structural, physiological, functional, and biochemical multimodal image fusion and intraoperative real-time update of image data, integrated with robots and indispensable to neurosurgical training, virtual simulation, surgical planning, intraoperative reality, and postoperative analysis of every neurosurgical procedure.

\section{Disclaimer}

The author reports no conflict of interest concerning the materials or methods used in this study or the findings specified in this paper.

\section{References}

1. Alavi A, Kung JW, Zhuang H: Implications of PET based molecular imaging on the current and future practice of medicine. Semin Nucl Med 34:56-69, 2004

2. Albayrak B, Samdani AF, Black PM: Intra-operative magnetic resonance imaging in neurosurgery. Acta Neurochir (Wien) 146:543-557, 2004

3. Altuchow NW: Encephalometric Investigation of Brain in Connection with Sex, Age and Cranium Size. Moscow, 1891

4. Ambrose J: Computerized transverse axial scanning (tomography). II. Clinical application. Br J Radiol 46:1023-1047, 1973

5. Andrew ER: Nuclear magnetic resonance and the brain. Brain Topogr 5:129-133, 1992

6. Apuzzo ML, Chen JC: Stereotaxy, navigation and the temporal concatenation. Stereotact Funct Neurosurg 72:82-88, 1999

7. Apuzzo ML, Sabshin JK: Computed tomographic guidance stereotaxis in the management of intracranial mass lesions. Neurosurgery 12:277-285, 1983

8. Bandettini PA, Wong EC, Hinks RS, Tikofsky RS, Hyde JS: Time course EPI of human brain function during task activation. Magn Reson Med 25:390-397, 1992

9. Barnett GH, Kormos DW, Steiner CP, Weisenberger J: Intraoperative localization using an armless, frameless stereotactic wand. Technical note. J Neurosurg 78:510-514, 1993

10. Baumgartner RW: History of neurovascular ultrasonography. Ther Umsch 54:24-30, 1997

11. Benabid AL, Lavallee S, Hoffmann D, Cinquin P, Demongeot
J, Danel F: Potential use of robots in endoscopic neurosurgery. Acta Neurochir Suppl (Wien) 54:93-97, 1992

12. Beyer T, Townsend DW, Brun T, Kinahan PE, Charron M, Roddy R, et al: A combined PET/CT scanner for clinical oncology. J Nucl Med 41:1369-1379, 2000

13. Black PM, Moriarty T, Alexander EA, Stieg P, Woodard EJ, Gleason PL, et al: Development and implementation of intraoperative magnetic resonance imaging and its neurosurgical applications. Neurosurgery 41:831-845, 1997

14. Braun V, Dempf S, Tomczak R, Wunderlich A, Weller R, Richter HP: Multimodal cranial neuronavigation: direct integration of functional magnetic resonance imaging and positron emission tomography data. Technical note. Neurosurgery 48:1178-1181, 2001

15. Coenen VA, Krings T, Weidemann J, Hans FJ, Reinacher P, Gilsbach JM: Sequential visualization of brain and fiber tract deformation during intracranial surgery with three-dimensional ultrasound: an approach to evaluate the effect of brain shift. Neurosurgery 56:133-141, 2005

16. Cormack AM: Representation of a function by its line integrals, with some radiological applications. J Appl Phys 34:2722-2727, 1964

17. Curie JP, Curie P: Développement par pression de l'électricité polaire dans les cristaux hémièdres à faces inclinées. C.R. Acad. Sci. (Paris) 91:294, 1880

18. Damadian R, Goldsmith M, Minkoff L: NMR in cancer: XVI. FONAR image of the live human body. Physiol Chem Phys 9:97-100, 108, 1977

19. Dandy WE: Roentgenography of the brain after the injection of air into the spinal canal. Ann Surg 70:397-403, 1919

20. Dandy WE: Ventriculography following the injection of air into the cerebral ventricles. Ann Surg 68:5-12, 1918

21. Dumoulin CL, Hart HR Jr: Magnetic resonance angiography in the head and neck. Acta Radiol Suppl 369:17-20, 1986

22. Dussik KT: On the possibility of using ultrasound waves as a diagnostic aid. Neurol Psychiat 174:153-168, 1942

23. Edler I, Hertz CH: The use of ultrasonic reflectoscope for the continuous recording of the movements of heart walls. 1954. Clin Physiol Funct Imaging 24:118-136, 2004

24. Enchev Y, Bozinov O, Miller D, Tirakotai W, Heinze S, Benes $\mathrm{L}$, et al: Image-guided ultrasonography for recurrent cystic gliomas. Acta Neurochir (Wien) 148:1053-1063, 2006

25. Enchev Y, Oi S: Historical trends of neuroendoscopic surgical techniques in the treatment of hydrocephalus. Neurosurg Rev 31:249-262, 2008

26. Enchev YP, Popov RV, Romansky KV, Marinov MB, Bussarsky VA: Cranial neuronavigation-a step forward or a step aside in modern neurosurgery. Folia Med (Plovdiv) 50:5-10, 2008

27. Enchev YP, Popov RV, Romansky KV, Marinov MB, Bussarsky VA: Effect of the type of image study (CT or MRI) on some parameters of neuronavigation-assisted procedures. Folia Med (Plovdiv) 50:47-52, 2008

28. Enchev YP, Popov RV, Romansky KV, Marinov MB, Bussarsky VA: Neuronavigated surgery of intracranial cavernomas-enthusiasm for high technologies or a gold standard? Folia Med (Plovdiv) 50:11-17, 2008

29. Enchev YP, Popov RV, Romansky KV, Marinov MB, Bussarsky VA: Role of neuronavigation in the resection of intracranial arteriovenous malformations. Folia Med (Plovdiv) 50:40-45, 2008

30. Ernst RR: Methodology of magnetic resonance imaging. Q Rev Biophys 19:183-220, 1987

31. Ernst RR: Nobel lecture. Nuclear magnetic resonance Fourier transform spectroscopy. Biosci Rep 12:143-187, 1992

32. Ganslandt O, Fahlbusch R, Nimsky C, Kober H, Möller M, Steinmeier R, et al: Functional neuronavigation with magnetoencephalography: outcome in 50 patients with lesions around the motor cortex. Neurosurg Focus 6(5):E5, 1999 
33. Gronemeyer DHW, Seibel RMM, Melzer A: Future of advanced guidance techniques by interventional CT and MRI. Minim Invasive Ther 4:251-259, 1995

34. Gronningsaeter A, Kleven A, Ommedal S, Aarseth TE, Lie T, Lindseth F: SonoWand, an ultrasound-based neuronavigation system. Neurosurgery 47:1373-1379, 2000

35. Grunert P, Darabi K, Espinosa J, Filippi R: Computer-aided navigation in neurosurgery. Neurosurg Rev 26:73-99, 2003

36. Grunert P, Müller-Forell W, Darabi K, Reisch R, Busert C, Hopf N, et al: Basic principles and clinical applications of neuronavigation and intraoperative computed tomography. Comput Aided Surg 3:166-173, 1998

37. Hahn EL: Spin echoes. Bull Am Phys Soc 24:13, 1949

38. Hasegawa BH, Lang TF, Brown EL: Object-specific attenuation correction of SPECT with correlated dual-energy X-ray CT. IEEE Trans Nucl Sci NS-40:1242-1252, 1993

39. Heilbrun MP, Roberts TS, Apuzzo ML, Wells TH, Sabshin JK: Preliminary experience with Brown-Roberts-Wells (BRW) computerized tomography stereotaxic guidance system. J Neurosurg 59:217-222, 1983

40. Hennig J, Nauerth A, Friedburg H: RARE imaging: a fast imaging method for clinical MR. Magn Reson Med 3:823-833, 1986

41. Horsley V, Clarke RH: The structure and functions of the cerebellum examined by a new method. Brain 31:45-124, 1908

42. Hounsfield GN: Computerized transverse axial scanning (tomography): Part I. Description of system. Br J Radiol 46:1016-1022, 1973

43. Jolesz FA: Interventional and intraoperative MRI: a general overview of the field. J Magn Reson Imaging 8:3-7, 1998

44. Kato A, Yoshimine T, Hayakawa T, Tomita Y, Ikeda T, Mitomo $\mathrm{M}$, et al: A frameless, armless navigational system for computer-assisted neurosurgery. Technical note. J Neurosurg 74:845-849, 1991

45. Kessler LW: Review of progress and applications in acoustic microscopy. J Acoust Soc Am 55:909-918, 1974

46. Kirschner M: Die Punktionstechnik und die Elektrokoagulation des Ganglion Gasseri. Über gezielte Operationen. Arch Klin Chir 176:581-620, 1933

47. Koivukangas J, Louhisalmi Y, Alakuijala J, Oikarinen J: U1trasound-controlled neuronavigator-guided brain surgery. J Neurosurg 79:36-42, 1993

48. Kuhl DE, Edwards RQ: Image separation radioisotope scanning. Radiology 80:653-661, 1963

49. Kwong KK, Belliveau JW, Chesler DA, Goldberg IE, Weisskoff RM, Poncelet BP, et al: Dynamic magnetic resonance imaging of human brain activity during primary sensory stimulation. Proc Natl Acad Sci U S A 89:5675-5679, 1992

50. Larmor J: Address of the president of the mathematical and physical section of the British Association for the Advancement of Science. Science 12:417-436, 1900

51. Lauterbur PC: All science is interdisciplinary-from magnetic moments to molecules to men (Nobel lecture). Angew Chem Int Ed Engl 44:1004-1011, 2005

52. Lauterbur PC: Image formation by induced local interactions: examples of employing nuclear magnetic resonance. Nature 242:190-191, 1973

53. Lauterbur PC: Progress in n.m.r. zeugmatography imaging. Philos Trans R Soc Lond B Biol Sci 289:483-487, 1980

54. Leeds NE, Kieffer SA: Evolution of diagnostic neuroradiology from 1904 to 1999. Radiology 217:309-318, 2000

55. Leksell L: A stereotactic apparatus for intracranial surgery. Acta Chir Scand 99:229-233, 1949

56. Lemons RA, Quate CF: Acoustical microscopy: biomedical applications. Science 188:905-911, 1975

57. Lindseth F, Kaspersen JH, Ommedal S, Lang $\varnothing$ T, Bang J, Hokland $\mathrm{J}$, et al: Multimodal image fusion in ultrasound-based neuronavigation: improving overview and interpretation by integrating preoperative MRI with intraoperative 3D ultrasound. Comput Aided Surg 8:49-69, 2003

58. Ludwig GD, Bolt RH, Heuter TF, Ballantine HT Jr: Factors influencing the use of ultrasound as a diagnostic aid. Trans Am Neurol Assoc 51:225-228, 1950

59. Mansfield P: Snapshot magnetic resonance imaging (Nobel lecture). Angew Chem Int Ed Engl 43:5456-5464, 2004

60. Mansfield P, Maudsley AA: Medical imaging by NMR. Br J Radiol 50:188-194, 1977

61. Matula C, Rössler K, Reddy M, Schindler E, Koos WT: Intraoperative computed tomography guided neuronavigation: concepts, efficiency, and work flow. Comput Aided Surg 3:174-182, 1998

62. Moniz EL: L’angiographie cérébrale. Paris: Masson \& Cie, 1934, pp 142-214

63. Moriarty TM, Quinones-Hinojosa A, Larson PS, Alexander E III, Gleason PL, Schwartz RB, et al: Frameless stereotactic neurosurgery using intraoperative magnetic resonance imaging: stereotactic brain biopsy. Neurosurgery 47:1138-1145, 2000

64. Nakao N, Nakai K, Itakura T: Updating of neuronavigation based on images intraoperatively acquired with a mobile computerized tomographic scanner: technical note. Minim Invasive Neurosurg 46:117-120, 2003

65. Nimsky C, Ganslandt O, Kober H, Buchfelder M, Fahlbusch $\mathrm{R}$ : Intraoperative magnetic resonance imaging combined with neuronavigation: a new concept. Neurosurgery 48:10821089, 2001

66. Nimsky C, Ganslandt O, Kober H, Möller M, Ulmer S, Tomandl B: Integration of functional magnetic resonance imaging supported by magnetoencephalography in functional neuronavigation. Neurosurgery 44:1249-1255, 1999

67. Ogawa S, Tank DW, Menon RS, Ellerman JM, Kim SG, Merkle $\mathrm{H}$, et al: Intrinsic signal changes accompanying sensory stimulation: functional brain mapping with magnetic resonance imaging. Proc Natl Acad Sci U S A 89:5951-5955, 1992

68. Oi S, Enchev Y: Neuroendoscopic foraminal plasty of foramen of Monro. Childs Nerv Syst 24:933-942, 2008

69. Rabi II, Zacharias JR, Millman S, Kusch P: Milestones in magnetic resonance: 'a new method of measuring nuclear magnetic moment'. 1938. J Magn Reson Imaging 2:131-133, 1992

70. Raju TN: The Nobel chronicles. 1979: Allan MacLeod Cormack (b 1924); and Sir Godfrey Newbold Hounsfield (b 1919). Lancet 354:1653, 1999

71. Rasmussen IA Jr, Lindseth F, Rygh OM, Berntsen EM, Selbekk T, Xu J, et al: Functional neuronavigation combined with intra-operative 3D ultrasound: initial experiences during surgical resections close to eloquent brain areas and future directions in automatic brain shift compensation of preoperative data. Acta Neurochir (Wien) 149:365-378, 2007

72. Reinhardt H, Meyer H, Amrein E: Computer aided surgery: Robotik für Hirnoperationen? Polyscope Plus 6:1-6, 1986

73. Reinhardt HF, Horstmann GA, Gratzl O: Sonic stereometry in microsurgical procedures for deep-seated brain tumors and vascular malformations. Neurosurgery 32:51-57, 1993

74. Riechert T, Wolff M: [A new directive apparatus for the coagulation of the ganglion Gasseri and other intracerebral procedures.] Acta Neurochir (Wien) 2:405-407, 1952 (Ger)

75. Roberts DW, Strohbehn JW, Hatch JF, Murray W, Kettenberger $\mathrm{H}$ : A frameless stereotaxic integration of computerized tomographic imaging and the operating microscope. J Neurosurg 65:545-549, 1986

76. Samset E, Hirschberg H: Neuronavigation in intraoperative MRI. Comput Aided Surg 4:200-207, 1999

77. Seynaeve PC, Broos JI: The history of tomography. J Belge Radiol 78:284-288, 1995

78. Shalit MN, Israeli Y, Matz S, Cohen ML: Intra-operative computerized axial tomography. Surg Neurol 11:382-384, 1979 
79. Sindwani R, Bucholz R: The next generation of navigational technology. Otolaryngol Clin North Am 38:551-562, 2005

80. Spiegel EA, Wycis HT, Marks M, Lee AJ: Stereotactic apparatus for operations on the human brain. Science 106:349350, 1947

81. Stevenson JG, Brandestini MA, Weiler T, Howard EA, Eyer M: Digital multigate Doppler with color echo and Doppler display-diagnosis of atrial and ventricular septal defects. Circulation 60:205, 1979

82. Takahashi S: [Rotation radiography and computer tomography.] Rinsho Hoshasen 21:1037-1045, 1976 (Jpn)

83. Talairach J, Hecaen H, David M, Monnier M, De Ajuriaguerra J: Recherches sur la coagulation thérapeutique des structures sous-corticales chez l'homme. Rev Neurol 81:4-24, 1949

84. Ter-Pogossian MM, Phelps ME, Hoffman EJ, Mullani NA: A positron-emission transaxial tomograph for nuclear imaging (PETT). Radiology 114:89-98, 1975

85. Tesla N: On electrical resonance. 1893. MD Comput 12:137140,1995

86. Townsend DW: Combined positron emission tomographycomputed tomography: the historical perspective. Semin Ultrasound CT MR 29:232-235, 2008

87. Tronnier VM, Wirtz CR, Knauth M, Lenz G, Pastyr O, Bonsanto MM: Intraoperative diagnostic and interventional magnetic resonance imaging in neurosurgery. Neurosurgery 40:891-900, 1997

88. Watanabe E, Watanabe T, Manaka S, Mayanagi Y, Takakura $\mathrm{K}$ : Three-dimensional digitizer (neuronavigator): new equipment for computed tomography-guided stereotactic surgery. Surg Neurol 27:543-547, 1987

89. Wells PN: Advances in ultrasound: from microscanning to telerobotics. Br J Radiol 73:1138-1147, 2000

90. Wells TH, Cosman ER, Ball RE: The Brown-Roberts-Wells (BRW) arc: its concept as a spatial navigation system. Appl Neurophysiol 50:127-132, 1987
91. Wesolowski JR, Lev MJ: CT: history, technology, and clinical aspects. Semin Ultrasound CT MR 26:376-379, 2005

92. Wild JJ, Reid JM: Further pilot echographic studies on the histologic structure of tumors of the living intact human breast. Am J Pathol 28:839-861, 1952

93. Young RF: Application of robotics to stereotactic neurosurgery. Neurol Res 9:123-128, 1987

94. Zaaroor M, Bejerano Y, Weinfeld Z, Ben-Haim S: Novel magnetic technology for intraoperative intracranial frameless navigation: in vivo and in vitro results. Neurosurgery 48:1100-1107, 2001

95. Zamorano LJ, Nolte LP, Kadi AM: Interactive intraoperative localization using infrared-based system. Neurol Res 15:290-298, 1993

96. Zernov DN: L'encéphalometrie. Rev Gen Clin Ther 19:302, 1890

97. Ziedses des Plantes BG: [Netherlands' contribution to the progress of medical research 1900-1950. Neuroradiography and neuro-electrology.] Ned Tijdschr Geneeskd 96:25262530, 1952 (Dutch)

98. Zimmermann M, Krishnan R, Raabe A, Seifert V: Robotassisted navigated neuroendoscopy. Neurosurgery 51:14461451,2002

Manuscript submitted April 16, 2009.

Accepted June 30, 2009.

Address correspondence to: Yavor Enchev, M.D., Ph.D., Medical University-Sofia, Department of Neurosurgery, University Hospital "Sv. Ivan Rilsky," 15, Boulv. "Acad. Ivan Geshov," 1431 Sofia, Bulgaria.email: dr.y.enchev@gmail.com. 